CrossMark $\leftarrow$ click for updates

Cite this: New J. Chem., 2016, 40, 4095

Received (in Montpellier, France)

17th December 2015,

Accepted 18th March 2016

DOI: 10.1039/c5nj03591k

www.rsc.org/njc

\section{Recent advances in the synthesis of hierarchically porous silica materials on the basis of porous glasses}

\author{
Alexandra Inayat, ${ }^{a}$ Björn Reinhardt, ${ }^{b}$ Jan Herwig, ${ }^{b}$ Christian Küster, ${ }^{b}$ Hans Uhlig, ${ }^{c}$ \\ Sharon Krenkel, ${ }^{d}$ Edda Raedlein ${ }^{d}$ and Dirk Enke*b
}

\begin{abstract}
The thermal phase separation and subsequent leaching of sodium borosilicate glasses is a well established route for the preparation of porous glasses exhibiting adjustable pore sizes in the range of $1 \mathrm{~nm}$ up to almost $1 \mu \mathrm{m}$ as well as a very flexible geometric shape. The combination of this route with a large spectrum of synthesis strategies for the implementation of an additional pore system enables the preparation of hierarchically porous glass-based materials. This review covers a wide range of preparative routes for hierarchically porous silica materials starting from the sodium borosilicate glass with a special emphasis on the very recent developments in this versatile field of materials engineering.
\end{abstract}

\section{Introduction}

Porous glasses are amorphous silica materials with a narrow pore size distribution in the range between 4 and $1000 \mathrm{~nm}$, large pore volumes and usually high mechanical stability. Similar to conventional glasses, porous glasses can be produced in various binder-free geometric shapes, e.g. as granulates, beads, plates, sticks, tubes, fibers, rings, etc. (Fig. 1). ${ }^{1}$

Porous glasses are used as mechanically stable, inert supports, ${ }^{2}$ e.g. for enzyme immobilisation,,$^{3,4}$ as transparent supports for photochemical applications, ${ }^{5,6}$ as reference materials for texture analytical methods like mercury intrusion, PALS or nitrogen physisorption $^{7}$ and also as a model material with well defined porosity for diffusion studies in porous media. ${ }^{8}$

The most common route for preparing porous glasses is the leaching of phase separated alkali borosilicate glasses, ${ }^{2}$ as schematically shown in Fig. 2 .

The resulting textural and mechanical product properties strongly depend on the composition of the initial glass, the temperature and the duration of the heat treatment for phase separation and the leaching (acidic extraction to remove the

\footnotetext{
${ }^{a}$ Institute of Chemical Reaction Engineering, University of Erlangen-Nürnberg, Egerlandstrasse 3, 91058 Erlangen, Germany. E-mail: alexandra.inayat@fau.de

${ }^{b}$ Institute of Chemical Technology, University of Leipzig, Linnéstrasse 3-4, 04103 Leipzig, Germany. E-mail: dirk.enke@uni-leipzig.de

${ }^{c}$ Institut für Nichtklassische Chemie, University of Leipzig, Permoserstr. 15, 04318 Leipzig, Germany.E-mail: uhlig@inc.uni-leipzig.de

${ }^{d}$ Department of Inorganic Nonmetallic Materials, Technische Universität Ilmenau, Gustav-Kirchoffstr. 6, 98693 Ilmenau, Germany.

E-mail: edda.raedlein@tu-ilmenau.de
}

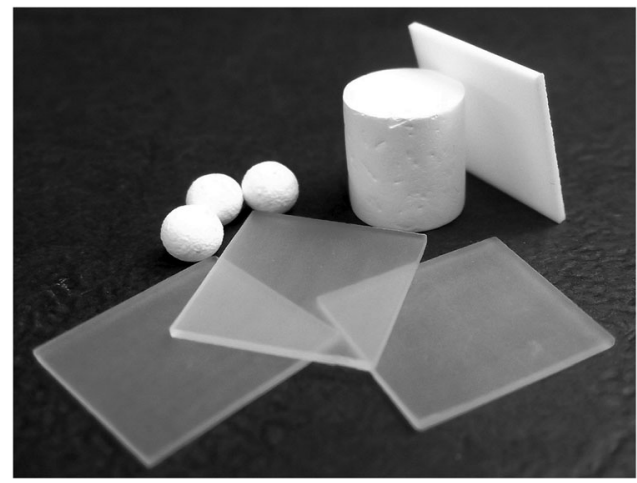

Fig. 1 Examples of the geometric forms of porous glass monoliths.

sodium borate phase followed by alkaline treatment to remove siliceous residues if desired) conditions. ${ }^{2}$

Typically, porous glasses prepared from phase separated alkali borosilicate glasses exhibit a monomodal pore size distribution. Recent studies in the field of porous glasses continue to focus on the controlled manipulation of their functional as well as textural properties. For example, magnetic porous glasses were prepared by implementing iron oxide contents between 6 and $9 \mathrm{wt} \% .^{9-11}$ These materials were used as a host matrix for different ferroelectrics $\left(\mathrm{NaNO}_{2}\right.$ and $\left.\mathrm{KNO}_{3}\right)$. The obtained nanocomposites were characterized by interesting ferroelectric and ferromagnetic properties. ${ }^{9}$ Another recent research example is the development of macroporous glasses on the basis of zirconia and zircon containing sodium borosilicate glasses. ${ }^{12}$ The zircon/zirconia additives influenced the phase separation process and led to increased pore sizes compared to 


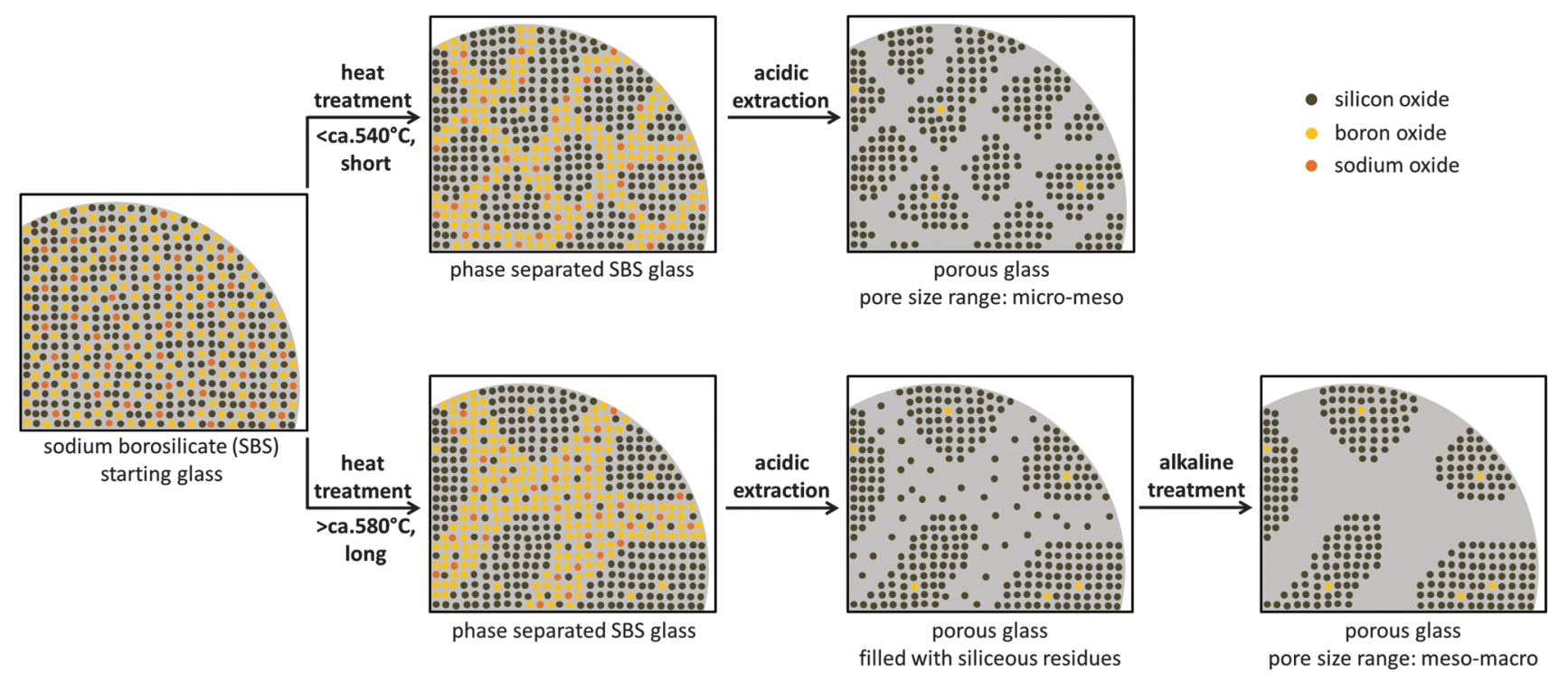

Fig. 2 Schematic illustration of the porous glass preparation by thermal phase separation and subsequent chemical leaching (acidic/alkaline extraction) of the sodium borosilicate glass.

unmodified porous glasses. As an advantageous feature, the zircon/zirconia additives increased the alkali resistance of the porous glasses by a factor of 3 to 4 .

Recently, the preparation of porous glass monoliths with an aligned pore system was facilitated via stretch forming. ${ }^{13}$ Further approaches for the modification of the textural properties of porous glasses, but with a special focus on obtaining hierarchical pore systems, ${ }^{14}$ were reviewed by us in $2013 .{ }^{15}$

Guillot et al. showed in a first study the potential of glasses with hierarchical macro- and mesoporosity for applications as supports in catalysis and solid phase extraction processes. ${ }^{16}$ The introduction of an additional MCM-41-like mesopore system into a macroporous glass resulted in an increase in catalytic activity and adsorption capacity after subsequent functionalisation with different silanes. Very recently, Galarneau and Fajula applied hierarchically porous silica monoliths, which were prepared via polymer-induced phase separation in a sol-gel process, as microreactors for process intensification in catalytic and adsorption processes. ${ }^{17}$ They showed several examples for the improvement of the performance resulting from the hierarchical structure of the monoliths.

In this present review we will upgrade our previous review from 2013 with several new approaches and scientific findings for the preparation of hierarchically porous silica materials based on porous glasses.

Throughout this article, we will distinguish between leachingbased pores and additional pores, which together form different hierarchical pore systems. Leaching-based pores are those pores formed by phase separation and subsequent leaching (extraction) of the glass. Additional pores are those pores created either through monolith formation or by different post-synthesis transformations discussed in the following sections. In those cases, where the porous glass particles are the building blocks of the glass monolith, the hierarchical pore system consists of (large) additional pores, which lead to (smaller) leaching-based pores. In those cases, where the additional pores are located inside of the original glass pore walls, e.g. after pseudomorphic transformation, the hierarchical pore system is composed of leachingbased pores, which lead to (smaller) additional pores.

\section{Routes to hierarchically porous materials based on porous glasses}

\subsection{Sintering and selective leaching}

2.1.1. Salt/filler sintering. A very common and easy way to prepare porous monoliths is based on the so-called filler principle, where inorganic salts, organic salts or polymers act as pore-forming agents during the monolith-forming sintering process. In the case of hierarchically porous glass monoliths, this salt sintering process for the manufacturing of open-pore glass monoliths is combined with the VYCOR-process ${ }^{18}$ as depicted in Fig. 3.

For the preparation of these hierarchically porous glass monoliths a phase separating sodium borosilicate glass powder is used as a starting material and then mixed with potassium sulfate or sodium chloride (but also organic salts or polymers can be applied), which are the filler salts. ${ }^{19}$ To obtain mechanically stable monoliths, a binder is added. Initially, a mixture consisting of glass powder, salt and a binder is mixed (by stirring) and pressed uniaxially at $100 \mathrm{MPa}$ into cylindrical plates (or other desired geometries). ${ }^{20}$ After drying, the "green" compacts are sintered for $30 \mathrm{~min}$ at $1043 \mathrm{~K}$ followed by rapid cool-down below the critical temperature of phase separation within the sodium borosilicate glass. Subsequently, the composites are slowly cooled in the furnace to room temperature to avoid stress in the glass.

Phase separation within the sintered glass particles is then initiated by an additional thermal treatment at temperatures chosen according to the desired leaching-based pore size. 

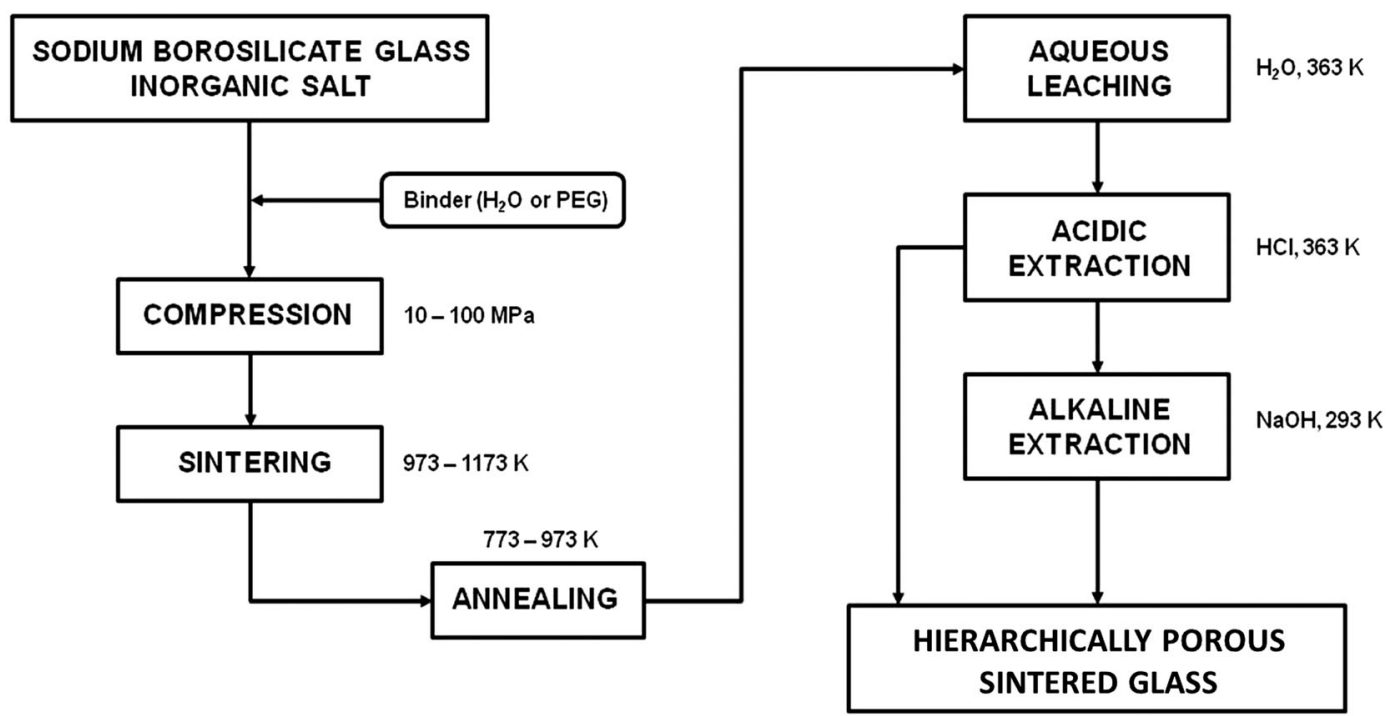

Fig. 3 General preparation scheme for hierarchically porous sintered glasses.

Afterwards, the inorganic salt is extracted with water to release the additional pore system, whose pore morphology can be adjusted by using different grain sizes and volume fractions of the filler salt.

The additional pore system created via the sintering route of glass particles according to the filler principle is characterized by pore sizes in the range between 3 and $500 \mu \mathrm{m} .{ }^{21}$ As shown in Fig. 4 the size distribution of the additional pores correlates well with the used salt (filler) grain fractions. Furthermore, an increase in the amount of salt results in an increase of the additional pore volume.
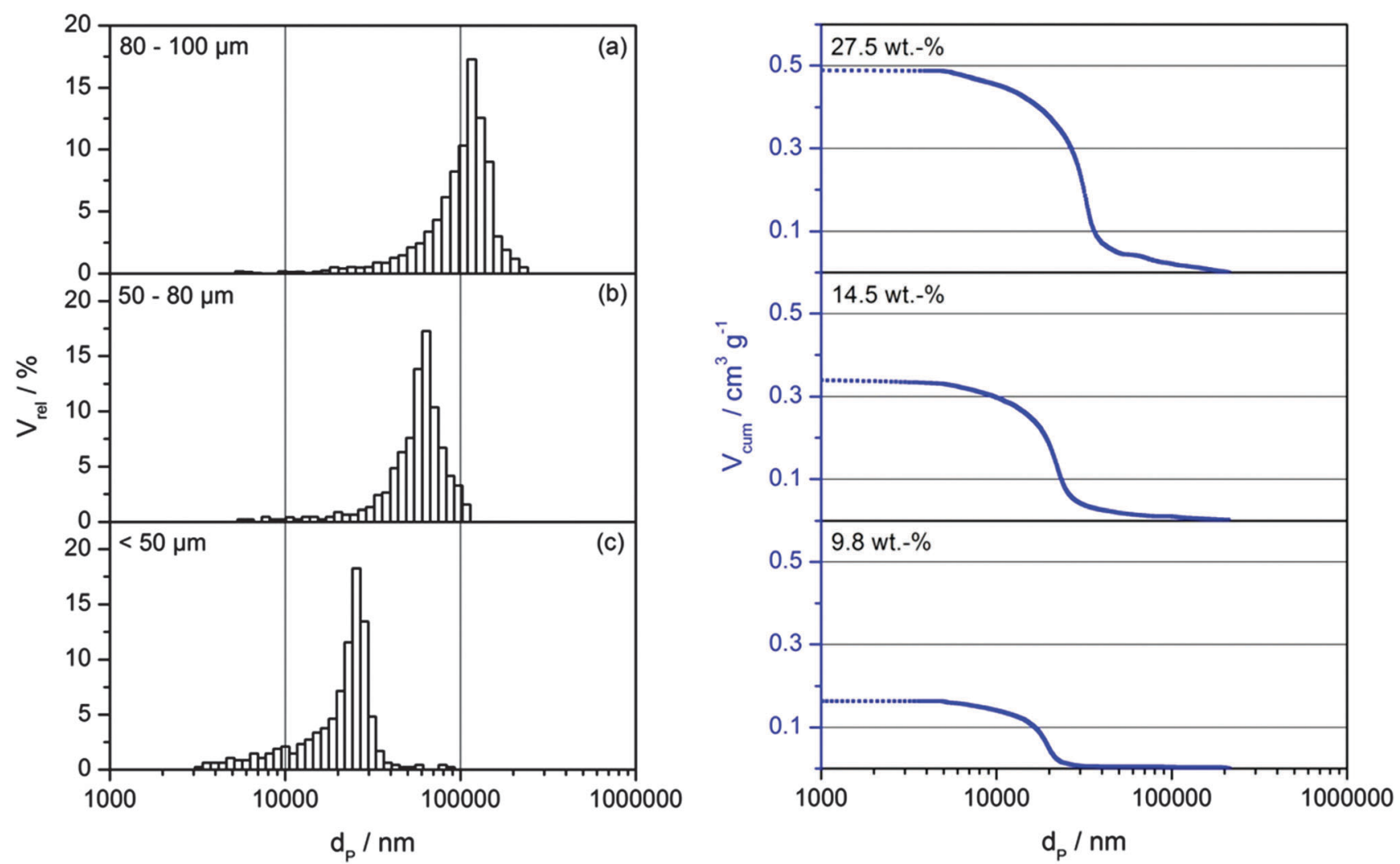

Fig. 4 Pore size distributions (from mercury intrusion) of the additional pore system in sintered glass samples prepared with salt grain fractions of different sizes (left: reprinted from ref. 19 with kind permission from The American Ceramic Society) and cumulative pore volume of the additional pore system by using different amounts of salt (right). 

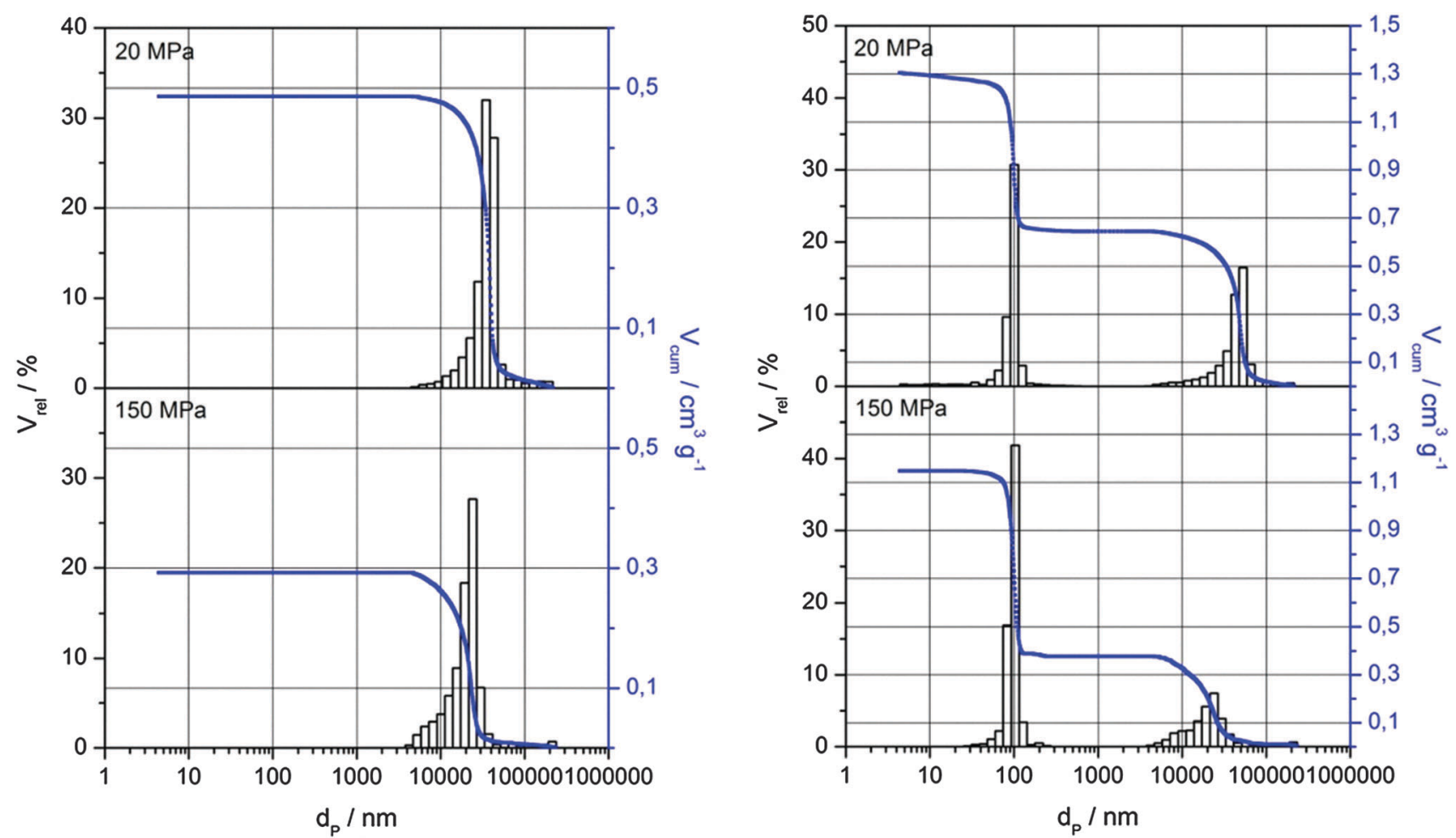

Fig. 5 Pore size distributions and cumulative pore volume (from mercury intrusion) of the additional pore system in sintered glass samples prepared by using different pressures during the sintering step before (left) and after (right) the annealing and extraction steps for the creation of the leaching-based pore system.

The pressure used to compress the glass-salt mixture has a strong influence on the resulting pore characteristics. A higher pressure leads to a closer packing of the particles. Due to the increased shear forces during compression, the mean particle size of the glass powder decreases. This results in a lower additional pore volume (Fig. 5), because the interparticle space is then partly filled with the smaller glass particles.

The leaching-based porosity within the phase separated walls of the sintered open-pore monoliths can be generated through an acidic extraction to remove the sodium-rich borate phase and an alkaline post-treatment, e.g. with $3 \mathrm{M} \mathrm{NaOH}$, to remove the debris of finely dispersed $\mathrm{SiO}_{2}$. The obtained pore size is not only influenced by the annealing and leaching conditions, but also by the applied filler salts. While sodium ions act relatively inert, the exchange of potassium ions between the glass and filler influences the phase separation behaviour significantly, resulting in a strictly microporous glass.

Based on this, hierarchically porous glasses of the type macro/micro, macro/meso and macro/macro were successfully prepared. ${ }^{19}$ The nitrogen adsorption isotherms and pore size distributions in Fig. 6 show that an increase of the annealing temperature (used for phase separation within the sodium borosilicate glass walls) results in an increase of the leachingbased pore diameter while the additional pore size (created through the sintering process) remains constant.

Leaching-based pore sizes between 1 and $70 \mathrm{~nm}$ and specific pore volumes of up to $0.5 \mathrm{~cm}^{3} \mathrm{~g}^{-1}$ were obtained in this way.
The micro/macro porous sample (Fig. 6a) exhibits a high specific surface area of $420 \mathrm{~m}^{2} \mathrm{~g}^{-1}$, which decreases to $28 \mathrm{~m}^{2} \mathrm{~g}^{-1}$ for the macro/macro porous sample (Fig. 6c).

By using different pressures during the sintering step (formation of the additional pores), the ratio between leaching-based and additional pore volume is adjustable. Fig. 5 (right) shows two examples of hierarchical monoliths with leaching-based to additional pore volume ratios of 50/50 (Fig. 5, right, top) and 70/30 (Fig. 5, right, bottom). These systems were prepared by using $9.8 \mathrm{wt} \%$ filler materials and a compressing pressure of 20 and $150 \mathrm{MPa}$, respectively, followed by the annealing and leaching steps as illustrated in Fig. 3. The specific surface area of these hierarchically porous monoliths ranges between 32 and $45 \mathrm{~m}^{2} \mathrm{~g}^{-1}$.

2.1.2. Foam replication. Two other innovative ways for the preparation of porous monoliths are the gas related foaming and the replication method. The gas related foaming can be realised by in situ gas evolution or by introducing an external gas into a glass suspension. The gas-related foaming needs a long-term stabilisation of the gas bubbles to increase the bubble size during foaming. At a specific gas bubble volume the walls of the bubbles tend to thin out, which leads to cracking of the walls and finally to an open-cell structure. ${ }^{22}$ In order to obtain stable monolithic glass foams, additives like binders are used to achieve an increased viscosity of the glass suspension and prevent a collapse of the foamed monoliths during the drying step. The stability of the monolithic foams is further increased through an additional sintering step. 

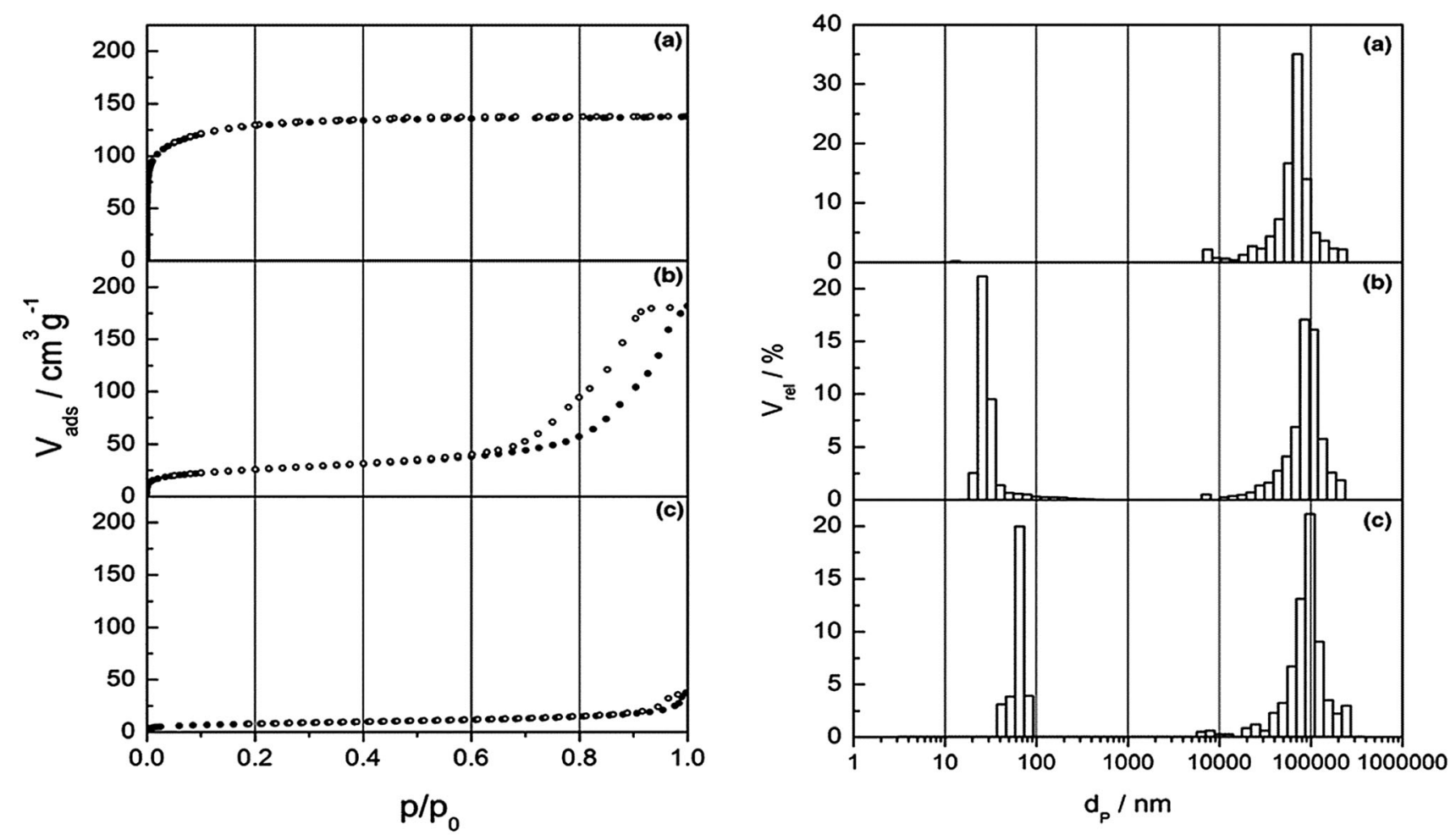

Fig. 6 Nitrogen physisorption isotherms (left) and pore size distributions from mercury intrusion (right) of hierarchically porous glass monoliths prepared by salt sintering using three different annealing temperatures; the hierarchical pore system consists of leaching-based and additional pores in the size ranges of (a) micro/macro, (b) meso/macro, (c) macro/macro, respectively; reprinted from ref. 19 with kind permission from The American Ceramic Society.

The second approach to foam monoliths is the replication method, which is based on the impregnation of a polymer foam with a suspension containing glass particles and different functional additives. In the case of glass monolith production, thin layers of a glass suspension are deposited on the polymeric struts. After drying, the polymer is burned out by thermal treatment and the resulting unstable calcined structure is sintered. The sintered product is a stable, macroporous opencell glass foam, featuring hollow struts due to the removal of the template. The more or less complete sintering of the individual glass particles in the struts at relatively low temperatures and short sintering times (compared to $\mathrm{Al}_{2} \mathrm{O}_{3}$ foams) results in a high mechanical stability of the obtained monoliths. The foams are exact replications of the template. There are several ways to impregnate the foam template, for example via dip-coating, drop-coating, as well as via chemical vapor deposition (CVD). The replication method has been known since 1963 and was patented by Schwartzwalder. ${ }^{23}$ The application of these open-cell foams was initially limited to catalyst supports in automobiles. Nowadays, there are several other important applications, e.g. transparent open-cell glass foams are used as light thinning internals in photo-bio reactors, where an algae solution is deposited in the pore structure, aerated and irradiated, to produce oxygen and biomass. ${ }^{24}$ A general scheme for the preparation of open-cell glass foams with a bimodal pore system is shown in Fig. 7.

In a first step, the additives (e.g. binders) are mixed with a solvent and heated under reflux, to obtain a clear solution.
After cooling, the glass particles are added and the mixture is stirred until a homogeneous slurry forms. A polyurethane foam of defined size is then immersed in the glass slurry and compressed. After the removal of excess slurry the impregnated material is dried, the template is removed by calcination and the remaining glass assembly is finally sintered. A subsequent thermal treatment between 500 and $700{ }^{\circ} \mathrm{C}$ initiates the phase separation within the sintered glass foam walls. The sodium-rich borate phase is removed by acidic extraction. An additional alkaline treatment with sodium hydroxide solution can be performed in order to remove secondary silica species from the leaching-based pores. ${ }^{25}$

The sintered glass monoliths exhibit a purely macroporous structure formed by connected hollow struts. This additional pore size is adjustable by using template foams of different strut sizes or different ppi (pores per inch) values. A photographic image as well as an electron microscopic (SEM) image of such a glass foam are shown in Fig. 8 .

The additional pore system exhibits pore diameters in the range between 400 and $1000 \mu \mathrm{m}$. Due to the shape and removal of the template, the sintered bodies show hollow struts with a triangular shape. The struts of the polymeric template are shaped concavely, which leads to voids with a convex shape in the replica as evident from the SEM image shown in Fig. 8 (right).

Those voids within the struts are around $50 \mu \mathrm{m}$ in diameter, which also correlates with the mercury pore size distribution shown in Fig. 9 (top left). Nitrogen physisorption measurements confirmed that no additional pores in the micropore range exist. Fig. 9 (top right) shows a typical type II nitrogen 


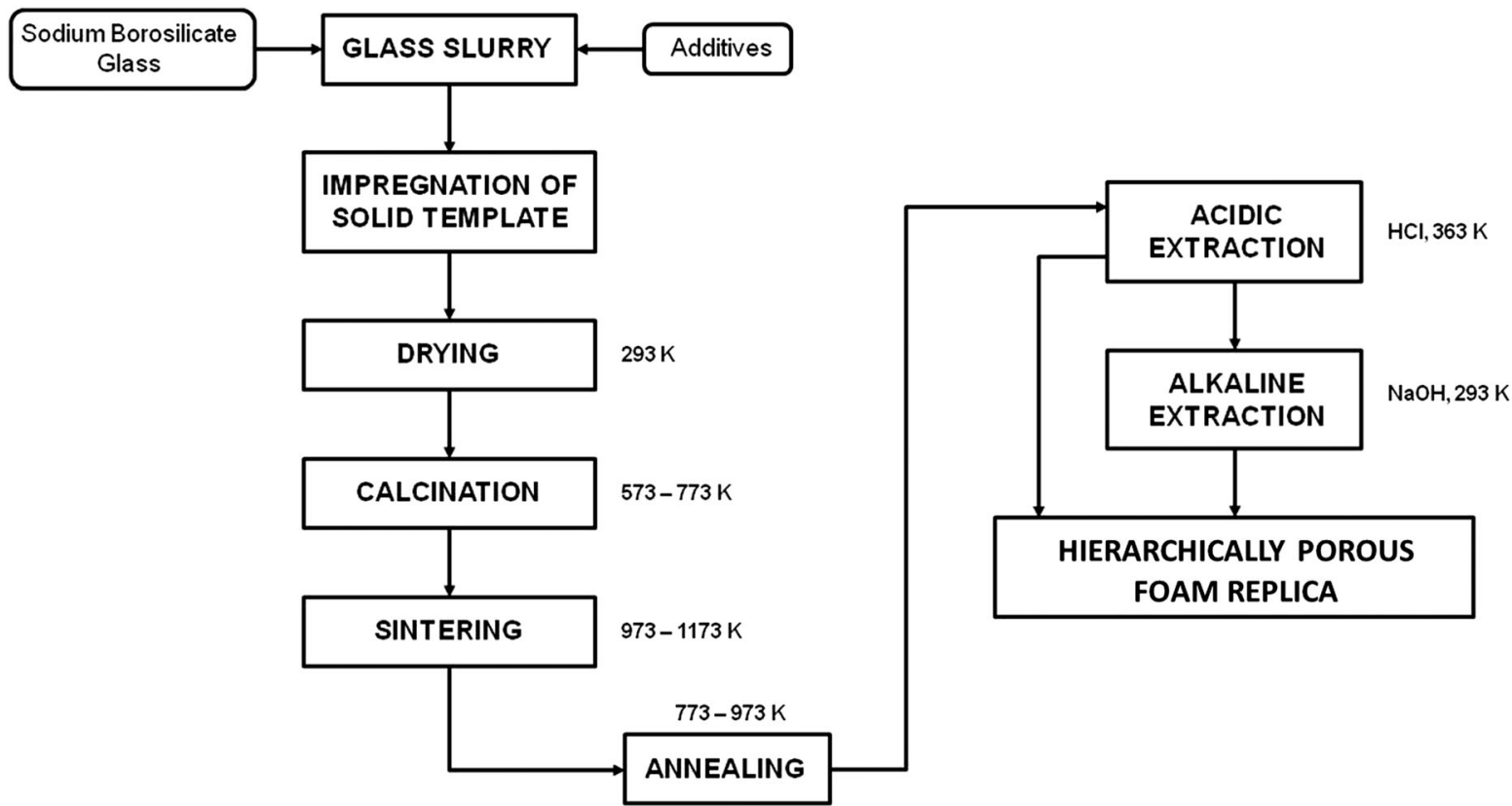

Fig. 7 General scheme for the preparation of hierarchically porous glass foams via foam replication.
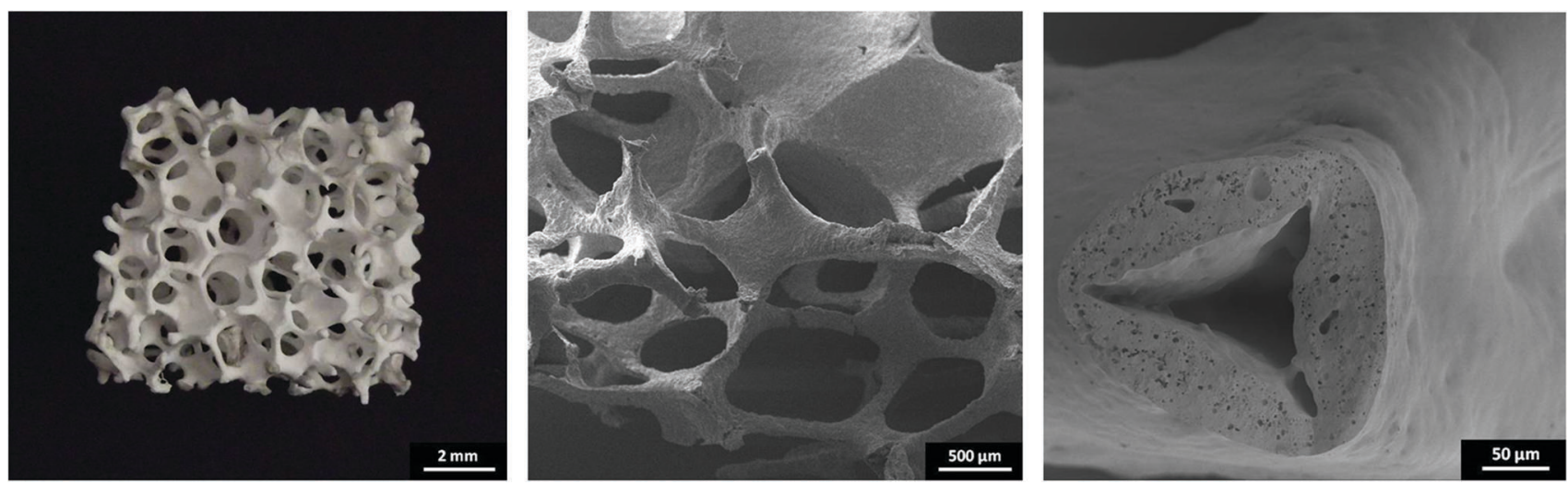

Fig. 8 Sintered macroporous glass foam before annealing and extraction; left: photographic image, middle: SEM image showing the additional porosity, and right: SEM image showing the hollow interior of a strut.

sorption isotherm with a very low adsorbed nitrogen volume of a sintered, purely macroporous monolith. The specific surface area of this sample is $4 \mathrm{~m}^{2} \mathrm{~g}^{-1}$.

The formation of the leaching-based pore system inside the solid phase of the struts was achieved by an additional thermal treatment (annealing) after sintering, followed by acidic/alkaline leaching. Fig. 9 (bottom left) presents the mercury pore size distribution of a typical hierarchically porous glass foam. The resulting monoliths show a bimodal hierarchical pore system, where the large additional pores are in the size range between 0.4 to $1.0 \mathrm{~mm}$ depending on the template cell structure. The leaching-based pore system is in the mesopore range depending on the conditions applied during the annealing and extraction step, respectively (Fig. 9, bottom right). By introducing this leaching-based pore system into the macroporous monolith the specific surface area could be increased from about $4 \mathrm{~m}^{2} \mathrm{~g}^{-1}$ up to a value of $95 \mathrm{~m}^{2} \mathrm{~g}^{-1}$.
Furthermore, the additional pore system of the monoliths (before annealing and extraction) was investigated using $3 \mathrm{D}-\mu$ computer tomography, which provides a three-dimensional reconstruction of the internal foam structure (Fig. 10 left). Single slices of the monolith can be displayed according to the number of pictures during measurement (Fig. 10, right). This allows the direct measurement of morphological parameters, such as average strut thickness, the glass layer thickness (which was initially deposited on the surface of the template material) and cell diameter distribution. The strut thickness depends on the glass layer thickness and ranges for the example shown in Fig. 10 from 100 to $150 \mu \mathrm{m}$ (hollow struts), whereas the layer thickness is $c a .20$ to $50 \mu \mathrm{m}$. Depending on the template, the cell size is about 1 to $2 \mathrm{~mm}$ in diameter.

2.1.3. Drawdown sintering of borosilicate glass tubes. The drawdown technique for glass tubes is a well known procedure 

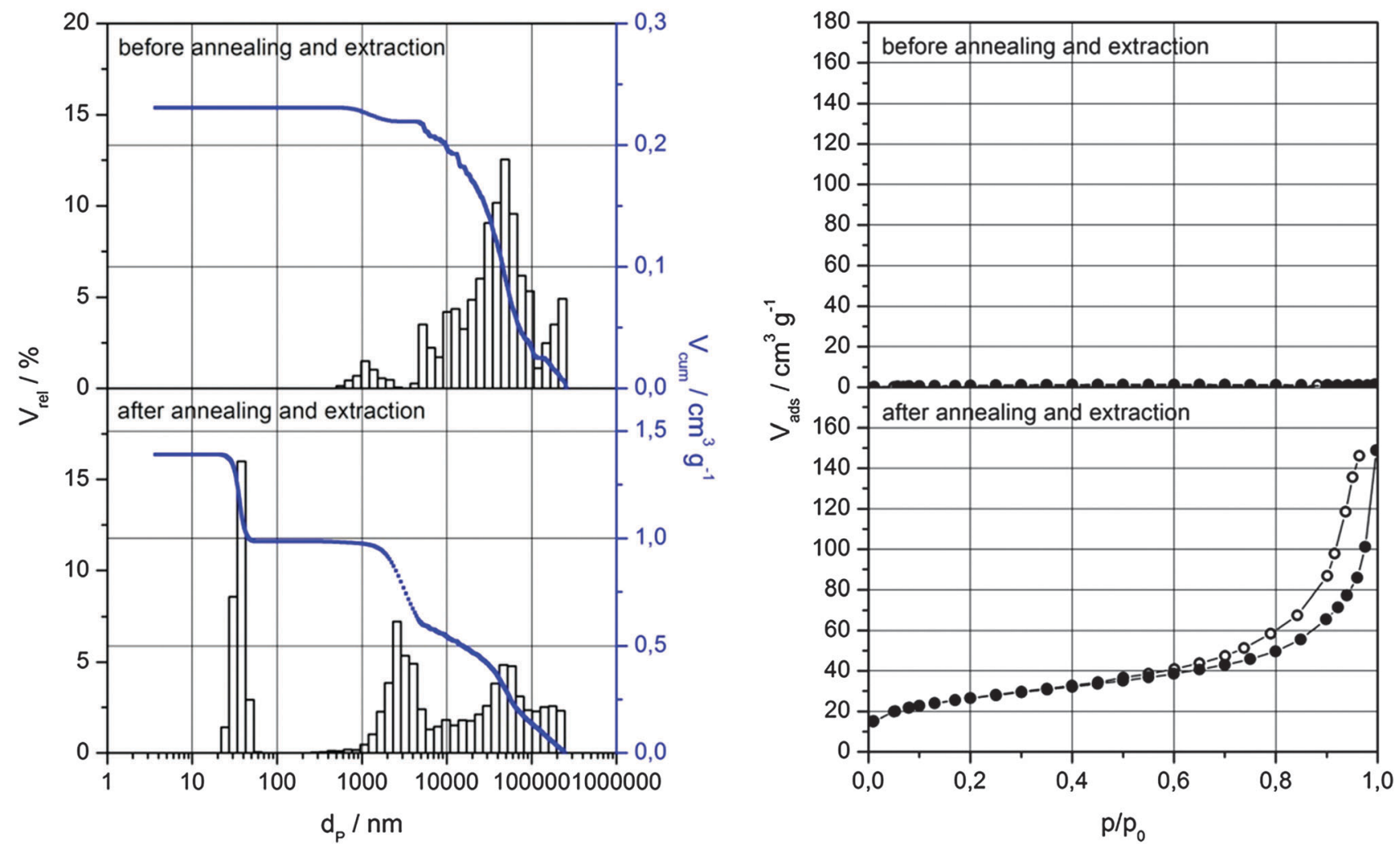

Fig. 9 Pore size distribution curves from mercury intrusion (left) and nitrogen sorption isotherms (right) of a macroporous sodium borosilicate glass foam before (top) and after (bottom) annealing and extraction. Adopted from ref. 25 with kind permission from Elsevier, Inc.

to obtain materials with aligned pores. As starting materials glass tubes and rods can be used. These materials can be bundled into any mixture to obtain complex geometries with aligned pores (see Fig. 11).

For fusion these glass bundles are heated to about 700-800 ${ }^{\circ} \mathrm{C}$ and drawn down, which leads to smaller bundles with diameters in the millimeter to micrometer range. Depending on the wall thickness of the glass tubes the ratio between walls and pores can be defined. To prevent the collapse of the aligned (additional) pores during the drawdown step, compressed air can be introduced into the green body.
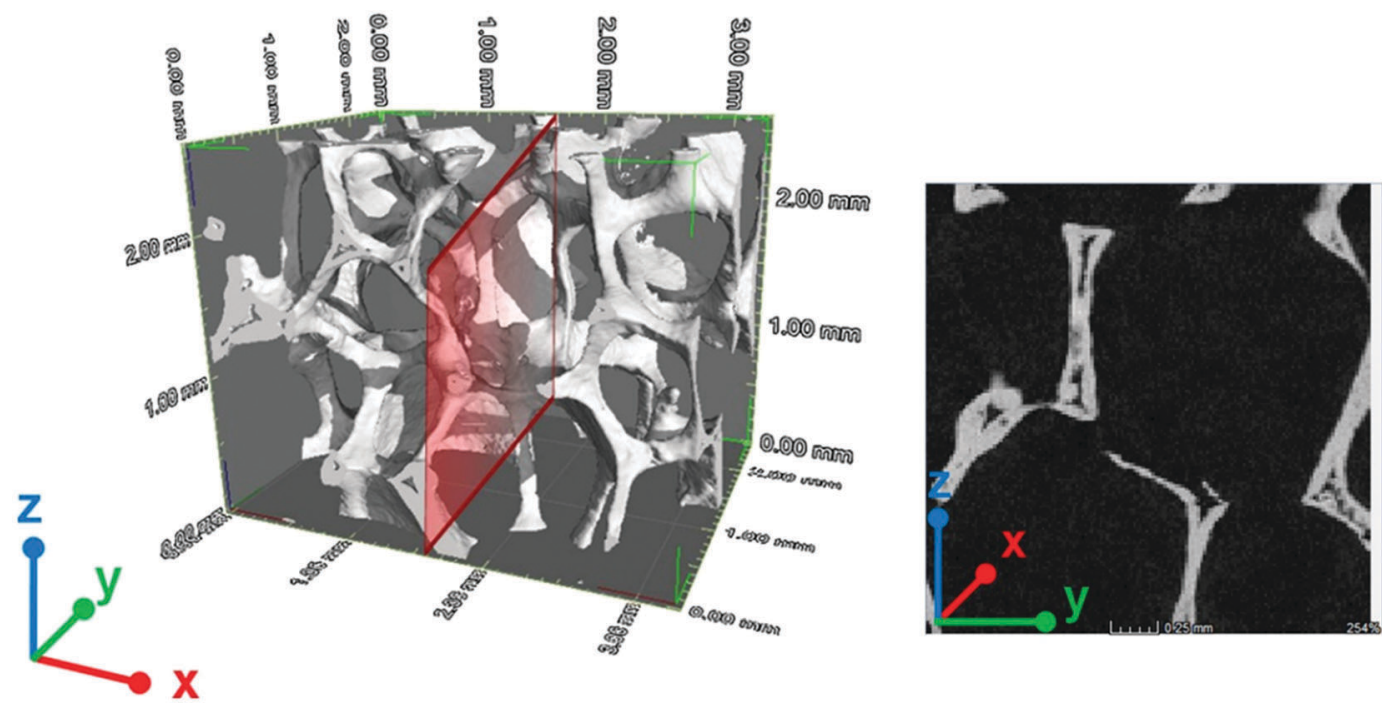

Fig. 10 Three-dimensional reconstruction of a sodium borosilicate glass monolith using 3D- $\mu \mathrm{CT}$ (left) and single layer of the monolith in the $x$-direction (right). Reproduced from ref. 25 with kind permission from Elsevier, Inc. 

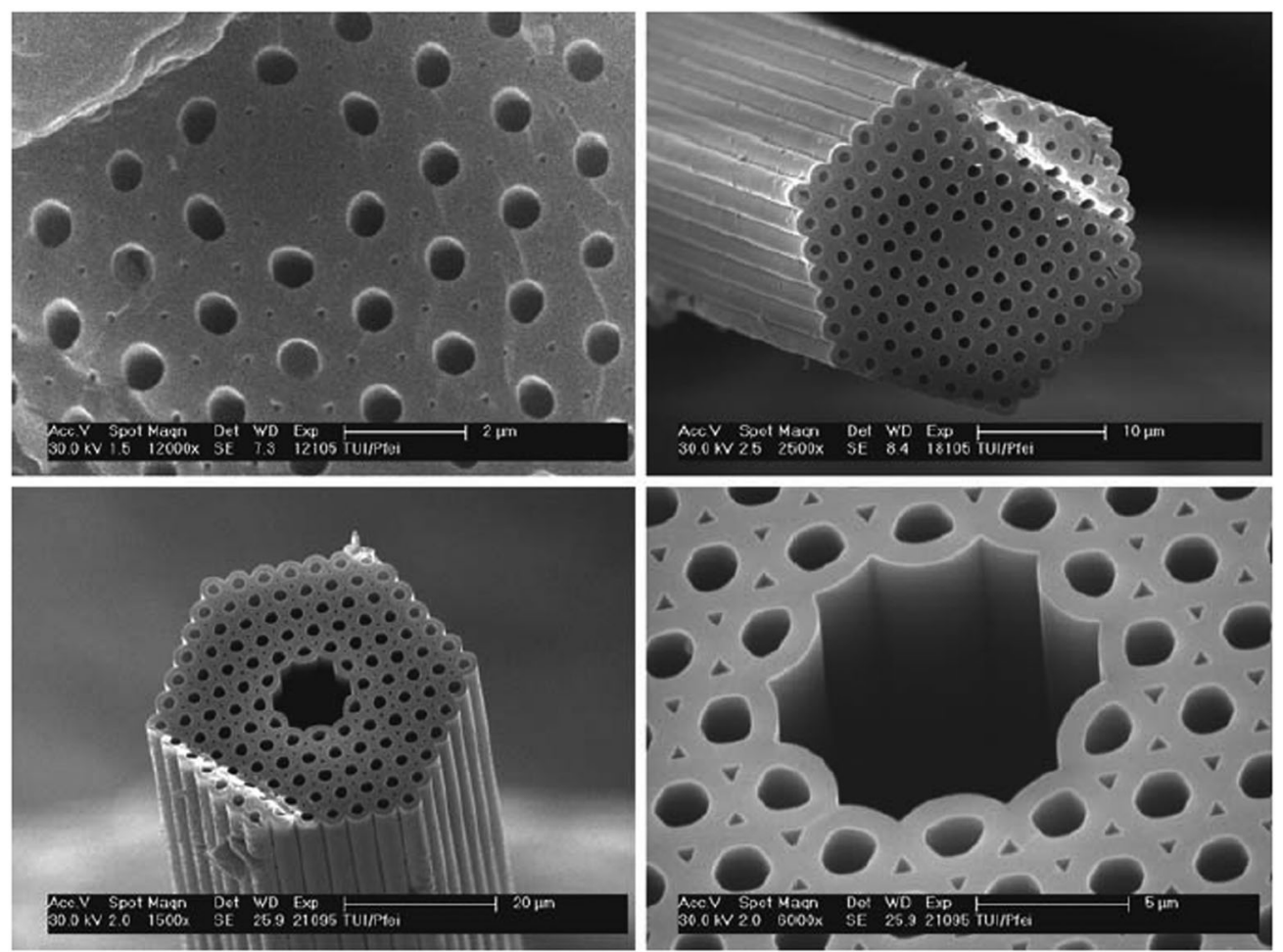

Fig. 11 Example of microstructured fibers with sub- $\mu$ m aligned pores (diameter of around $900 \mathrm{~nm}$ ) and triangular intertube pores (gussets, ca. $200 \mathrm{~nm}$ ). Reproduced from ref. 26 with kind permission from Springer Science and Business Media.

The drawdown process can be subdivided into three steps, shown schematically in Fig. 12. First, a high-quality starting material (tubes or rods) with small deviations in form has to be bundled and fixed. Then, the preformed glass bundle will be locally heated up to the softening point of the glass and drawn down with a certain feed to drawing ratio in order to control the final diameter of the bundle. ${ }^{26,27}$

The final geometry and porosity of the drawn bundle is determined by the starting materials, e.g. rods or tubes, and their arrangement within the bundle. How fast a glass can be drawn depends on the viscosity of the glass, which decreases with increasing temperature. In general, the drawing temperature should be in the range of the softening point of the glass in order to prevent the collapse of the tubes, which can lead to deformations of and within the bundles as well as closure of the glass tube channels (additional pores). Furthermore, the process temperature and sample residence time in the furnace allow to control the closure or preservation of the gussets (interstices between 3 tubes or rods). Gusset closure reduces the specific additional pore volume, but results in more stable glass bundles with a uniform additional pore size if only the internal tube channels are preserved.

A nice feature of this technique is that the process can be repeated several times to create more complex or smaller geometries by fusing bundles of bundles. The use of hexagonal or triangular bundles allows the combination of hundreds and even thousands of micro tubes in one sample. The example shown in Fig. 13 represents a section of 37 bundles of 37 glass tubes each, which are fused together to obtain 1369 aligned

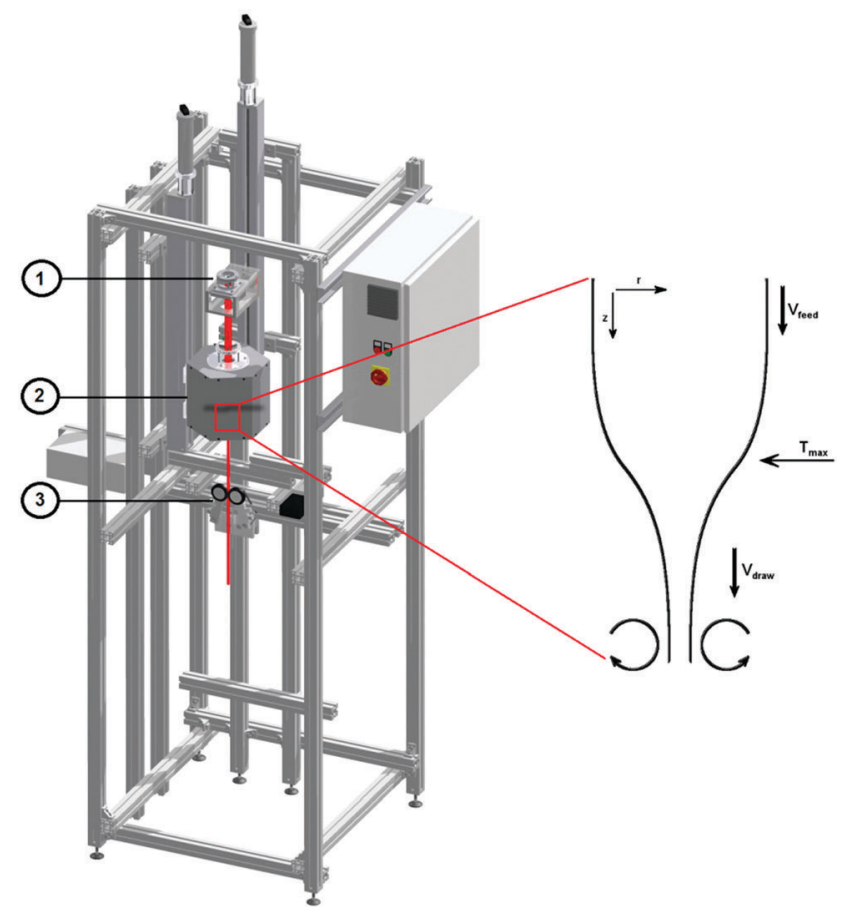

Fig. 12 Scheme of the glass drawing process (1 feeding apparatus, 2 hottest zone, 3 drawing rolls); reproduced from ref. 27 with kind permission from the Society of Glass Technology.

macropores. Such systems can be used as optical devices or in medical and biochemical applications. ${ }^{26,27}$ 


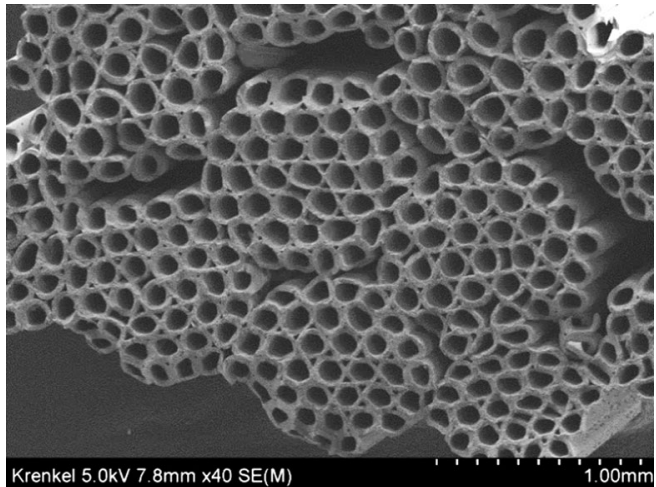

Fig. 13 SEM image of a section of 1369 glass tubes bundled in one monolith consisting of phase separated and leached borosilicate glasses.

The tube wall thickness as well as the diameter and volume of the additional (tube) pores can be adjusted by pressing air into the tube interior during the drawing process. Increasing air pressure leads to thinner tube walls and thus larger specific additional pore volumes.

To create glass bundles using a hierarchical pore system via the drawing process, phase separating borosilicate glass tubes or rods have to be used as the starting material. The resulting hierarchical material is schematically illustrated in Fig. 14 and combines a high mass transfer in the aligned (additional) macropores with a high surface area created by the smaller (leaching-based) pores in the glass tube walls. This leachingbased pore system can be used to implement various functions, e.g. for immobilization of catalysts or dyes. Such dyes can be used in $\mathrm{pH}$-sensors or for the detection of oxygen.

Depending on the initial glass composition the phase separation within the glass tube walls can take place already during the drawdown process or afterwards in a separate but much better controllable heat treatment step. Glass compositions with an upper phase separation temperature limit above the glass softening point lead to phase separation during the drawdown process. For the (typical) sodium borosilicate glass composition of $70 \mathrm{wt} \% \mathrm{SiO}_{2}, 23 \mathrm{wt} \% \mathrm{~B}_{2} \mathrm{O}_{3}$, and $7 \mathrm{wt} \% \mathrm{Na}_{2} \mathrm{O}$ the upper phase separation temperature limit $\left(\mathrm{ca} .750{ }^{\circ} \mathrm{C}\right)$ is within the range of the softening temperature $\left(\mathrm{ca} .670{ }^{\circ} \mathrm{C}\right)$.

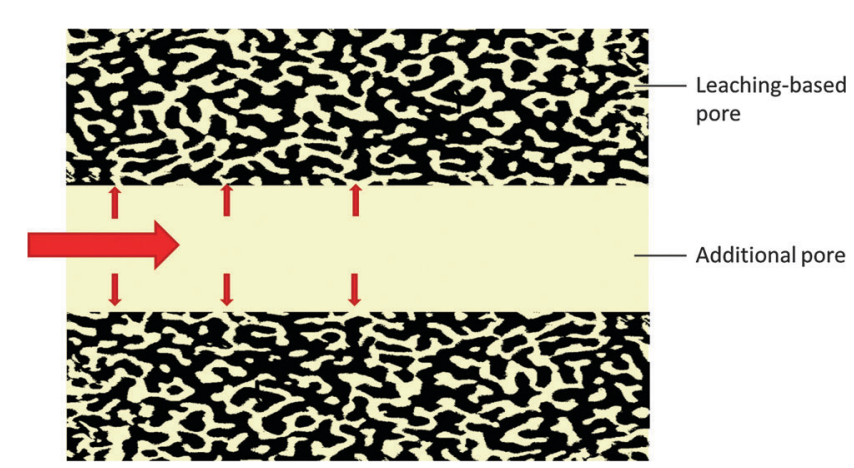

Fig. 14 Schematic illustration of the connectivity between one aligned additional pore (glass tube channel) and the leaching-based pores in the glass tube walls.
Therefore, at temperatures above $750{ }^{\circ} \mathrm{C}$, a glass bundle can be obtained without simultaneous phase separation. The advantage of separate glass drawing and phase separation steps is the independent control of the two different pore systems. The final geometry, the additional pore size and the length of the monolith can be influenced during the drawing process. The size of the leaching-based pores in the glass tube walls can be adjusted between 1-500 $\mathrm{nm}$ through the temperature and time of the subsequent phase separation and leaching treatments. ${ }^{27}$

However, using phase separating glass in the drawdown process also creates several problems. Firstly, the composition of the starting glass tubes/rods needs to be homogeneous without any phase separated regions. If this is not the case then the softening point fluctuates locally and the product cannot be drawn in a uniform manner. Secondly, the diameter of the starting rods or tubes should not deviate along the length and the rods or tubes should be perfectly straight, otherwise proper bundling of the material is not possible and leads to instable monoliths. Commercial glass tubes fulfil these conditions easily, for lab scale model glasses geometric perfection can be challenging.

Moreover, borate tends to evaporate from the glass during the high-temperature drawdown process. This leads to smaller leaching-based pore radii on the bundle surface and increases the probability of cristobalite crystallisation. A borax coating on the preformed tubes and rods can reduce these effects. Furthermore, the destruction-free leaching of such complex geometric shapes is still difficult compared to e.g. the extraction of compact granules. Mild extraction conditions $(1 \mathrm{M} \mathrm{HCl}$ and slow temperature increase to $90{ }^{\circ} \mathrm{C}$ ) have to be applied in order to obtain stable monoliths with a bimodal pore structure (see Fig. 15). ${ }^{27}$

In summary it can be stated that the combination of the draw down technique with phase separating borosilicate glass results in the following features: ${ }^{27}$

- Flexible geometry via combination of bundled tubes and/or rods with lengths up to $1 \mathrm{~m}$ ( $\varnothing_{\text {bundle }} \geq 1 \mathrm{~mm}$ ) or $8 \mathrm{~m}\left(\varnothing_{\text {bundle }} \leq 1 \mathrm{~mm}\right)$

- Controllable (additional) macropore size from $200 \mathrm{~nm}$ up to millimeters,

- Additional macropores are unidirectionally aligned,

- Glass tube walls are porous, which results in hierarchical porosity,

- Monoliths with higher surface area compared to glass tube bundles without porous walls,

- Controllable leaching-based pore size in the range of 1-500 nm, random orientation.

2.1.4. Camphene route: freeze-casting. Freeze-casting is a templating technique for the preparation of porous monoliths by using solidified (frozen) solvents. This method has been of great interest for many research groups during the past few years, because it allows the preparation of an oriented pore system with high porosity. ${ }^{28}$ This technique consists of freezing a liquid suspension, followed by sublimation of the solidified (frozen) phase with subsequent calcination and sintering of the obtained monoliths for pore wall consolidation. In this way a porous structure is obtained, exhibiting unidirectional 

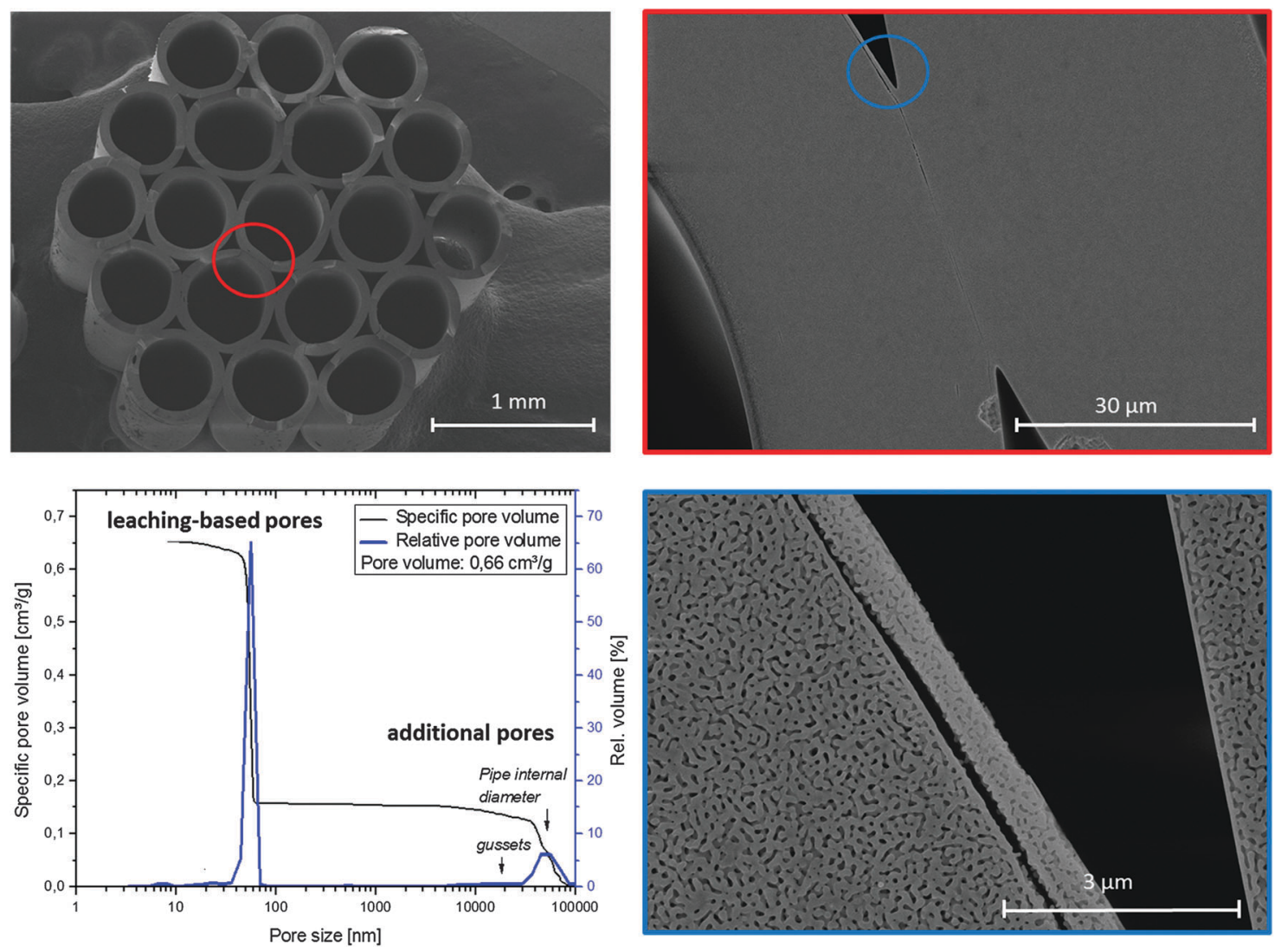

Fig. 15 SEM images in different magnifications and pore size distributions (bottom, left) measured via mercury intrusion of a 19 tube bundle after drawing, heat treatment and acidic+alkaline extraction; reproduced from ref. 27 with kind permission from the Society of Glass Technology.

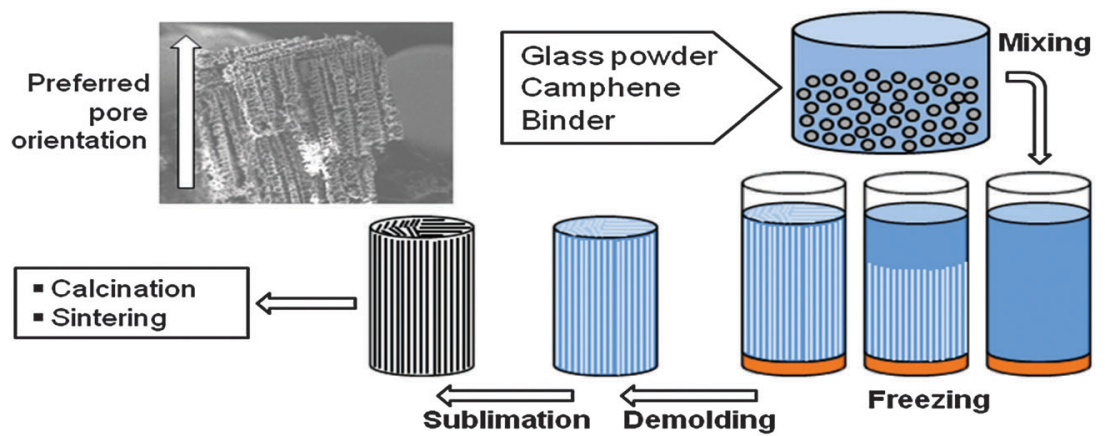

Fig. 16 Experimental procedure for the preparation of porous glass monoliths by freeze-casting; reproduced from ref. 29 .

channels in the case of unidirectional freezing, where the pores are the replicas of the solvent crystals. The structural properties of the solvent in its solid state will define the main appearance of the resulting porous structure.

The preparation of freeze-casted monoliths follows the general scheme shown in Fig. 16. The solvent (here: camphene), a glass powder and polystyrene as a soluble binder and phase separating agent are mixed at $60{ }^{\circ} \mathrm{C}$. The unidirectional freezing of the slurry is carried out below the melting temperature of the solvent. Due to the application of a temperature gradient the solvent crystals are forced to grow vertically along the direction of this gradient. The solidified green body is then removed from the mold and the camphene is sublimed at room temperature. ${ }^{29}$

The sublimation of camphene leads to dendritically shaped (additional) pores as shown in Fig. 17 (left). Depending on the freezing conditions, in particular the freezing temperature and the freezing velocity, a variation in the morphology and sizes of the resulting additional pores is possible. The pore size decreases with the increasing growth rate of the camphene crystals (Fig. 17, right). This inversely proportional relationship can be described by a power law. ${ }^{30}$

The freeze-casting method can be applied on many ceramic or glassy powders like alumina, titania and ceria. Using phase 

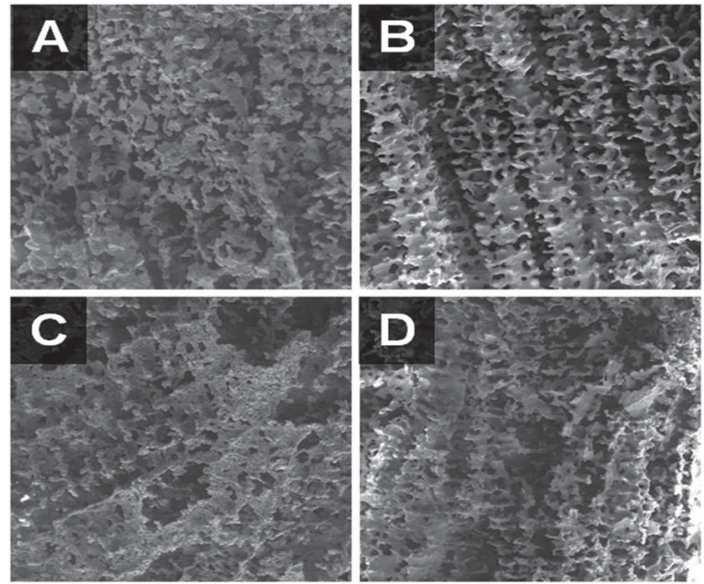

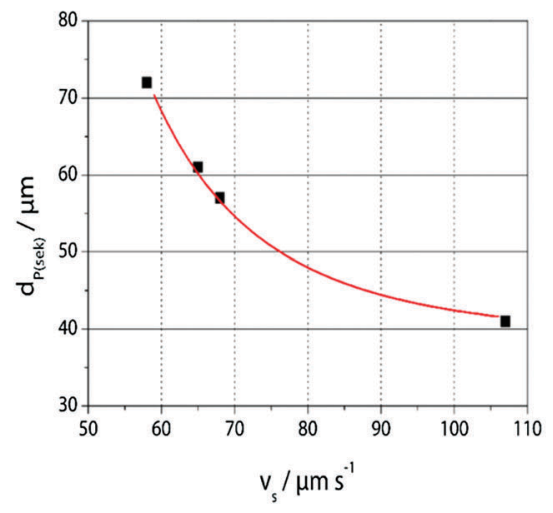

Fig. 17 Left: SEM images of the additional pore system in porous glass monoliths prepared by freeze-casting at different freezing velocities: (A) 58 , (B) 65 , (C) 67 and (D) $107 \mu \mathrm{m} \mathrm{s}^{-1}$; right: additional pore widths as a function of the freezing velocity; reproduced from ref. 29.

separating glasses enables the preparation of hierarchically porous materials whose leaching-based pore system can be adjusted on the basis of the annealing and leaching conditions. In this way, hierarchically porous monoliths with a leachingbased pore diameter of $50 \mathrm{~nm}$, a leaching-based pore volume of $0.45 \mathrm{~cm}^{3} \mathrm{~g}^{-1}$ and a specific surface area of $38 \mathrm{~m}^{2} \mathrm{~g}^{-1}$ were prepared. ${ }^{29}$ The respective pore size distribution is shown in Fig. 18.

2.1.5. Ionotropic gelation. It is a very recent finding that large silica beads in the range of 2 to $4 \mathrm{~mm}$ with a bimodal pore system including leaching-based pores between 20 and $120 \mathrm{~nm}$ as well as additional pores with diameters between 1 to $50 \mu \mathrm{m}$ can be synthesized via ionotropic gelation ${ }^{31}$ of a phase separable sodium borosilicate glass followed by subsequent thermal and leaching treatment. ${ }^{32}$ The synthesis route is presented in Fig. 19.

The sodium borosilicate glass consisting of approximately 62 wt $\% \mathrm{SiO}_{2}, 30$ wt $\% \mathrm{~B}_{2} \mathrm{O}_{3}, 7$ wt $\% \mathrm{Na}_{2} \mathrm{O}$ and $1 \mathrm{wt} \% \mathrm{Al}_{2} \mathrm{O}_{3}$ was first fractionated into different particle sizes. These powders

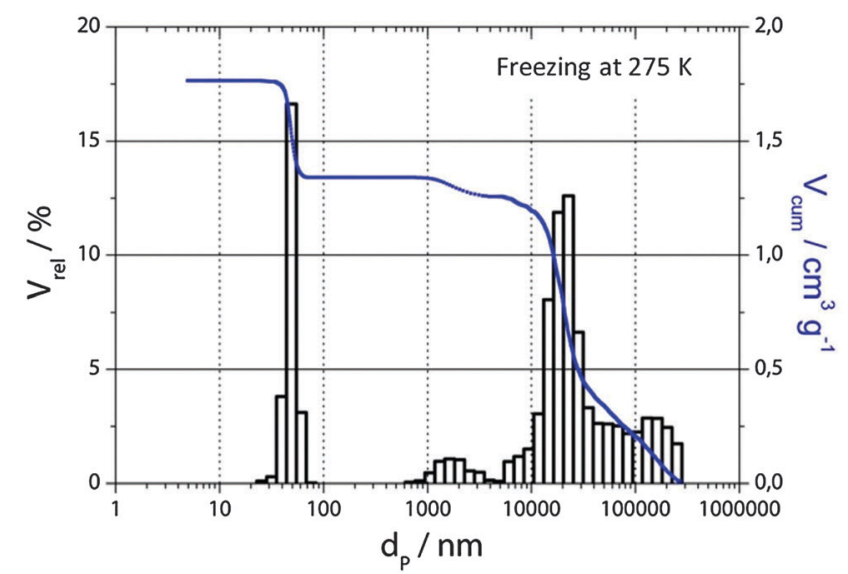

Fig. 18 Pore size distribution and cumulative pore volume of a hierarchically porous glass monolith prepared via a combination of freeze-casting, phase separation and extraction; reproduced from ref. 29.

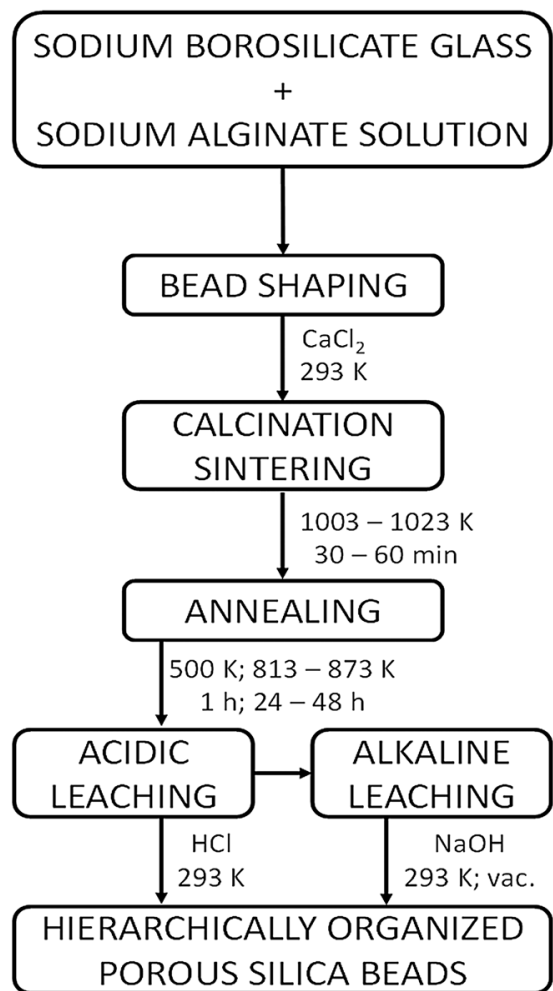

Fig. 19 General scheme for the preparation of hierarchically organized silica beads via ionotropic gelation.

were mixed with an aqueous sodium alginate solution to obtain a glass suspension. Subsequently this mixture was dropped into a calcium salt solution initiating spontaneous gelation (ionotropic gelation) through which each droplet formed a solid sphere. After drying stable spherical shapes were obtained, which showed only a small shrinkage in the following sintering process between 660 and $760{ }^{\circ} \mathrm{C}$. In the next step the glass beads were annealed at several temperatures between 540 and $620{ }^{\circ} \mathrm{C}$ for 24 hours. Finally, the shaped material underwent the typical steps of the VYCOR process. 

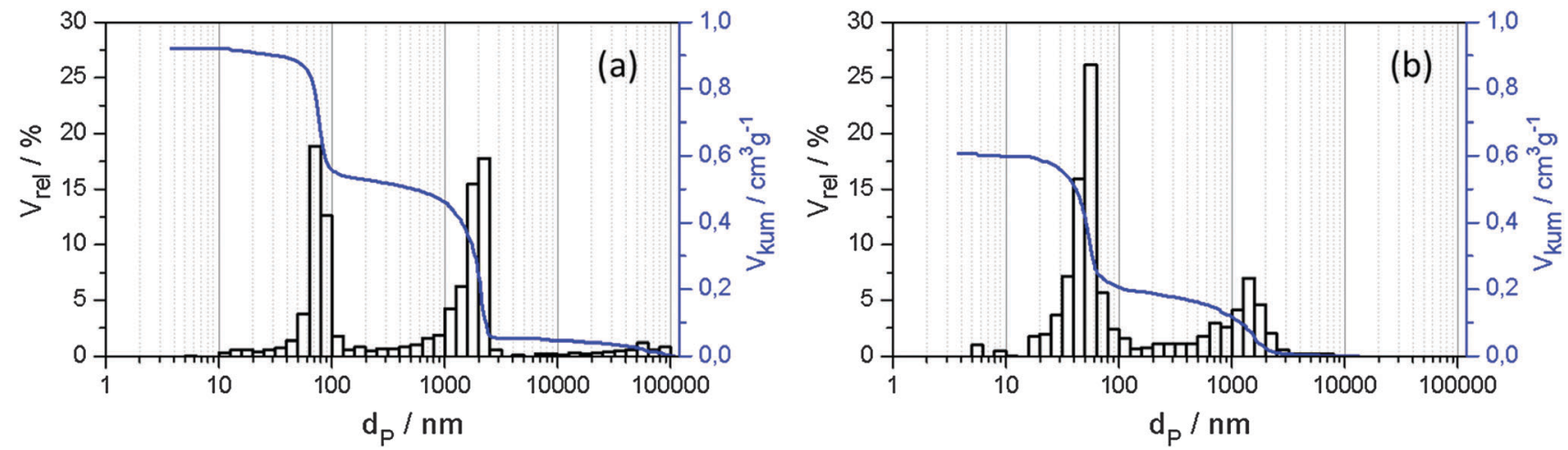

Fig. 20 Pore size distributions from mercury intrusion under two different sintering conditions: $700{ }^{\circ} \mathrm{C}$ for $1 \mathrm{~h} \mathrm{(a)}$ and $740{ }^{\circ} \mathrm{C}$ for $1 \mathrm{~h}(\mathrm{~b})$ of the spherical glass particles obtained by ionotropic gelation.

The results from mercury intrusion (Fig. 20) show that the beads are characterized using a bimodal pore system. Taking into consideration that a very broad particle size distribution was used (sieving fraction of $c a .1 \mu \mathrm{m}$ to $32 \mu \mathrm{m}$ ) in the sintering step, the size distribution of the additional pores is rather defined. Sintering at higher temperatures $\left(740^{\circ} \mathrm{C}\right)$ led to tougher materials with less pore volume for the additional pores and a shift in pore size towards smaller dimensions (Fig. 20(b)). The sintering process followed by the typical steps for VYCOR glass preparation resulted in leaching-based pores with diameters between 20 and $120 \mathrm{~nm}$. The SEM image in Fig. 21(b) of a sintered glass bead (prepared on the basis of a $80-100 \mu \mathrm{m}$ glass fraction) clearly shows the additional pore system between the distinctive glass particles. In Fig. 21(c) the leaching-based pore system with the typical spongy microstructure is presented exhibiting an average pore diameter of $70 \mathrm{~nm}$.

\subsection{Pseudomorphic transformation}

The (pseudomorphic) transformation of porous glass monoliths is an option to produce geometric shapes with a hierarchical pore system without the need for binder materials or mechanical forces. In the course of a pseudomorphic transformation the matrix material is converted into other structures while the original geometric shape and - in the very precise definition also the initial matrix pore system (= leaching-based pore system) remain unchanged, i.e. only the matrix pore walls are transformed.

Thus, in the case of porous glasses, an ideal pseudomorphic transformation into a porous material (e.g. zeolite or MCM-41) leads to a sponge-like transport pore system originating from the leaching-based glass pore system, which leads to the additional pore system present in the transformed leaching-based pore walls (Fig. 22).

Since the porous glass is mainly an amorphous $\mathrm{SiO}_{2}$ network, it offers the possibility for a complete or partial dissolution and precipitation of the siliceous building blocks of the glass walls to form new silica-containing structures like zeolites or micellar templated silica (MTS). However, it depends on the final location of the transformed silica material if a hierarchical pore system results from this transformation. Accordingly, for a successful synthesis of hierarchical pore systems by direct pseudomorphic transformation (see Section 2.2.1), controlling the building block diffusion during the dissolution process is a key factor. If a direct pseudomorphic transformation is not
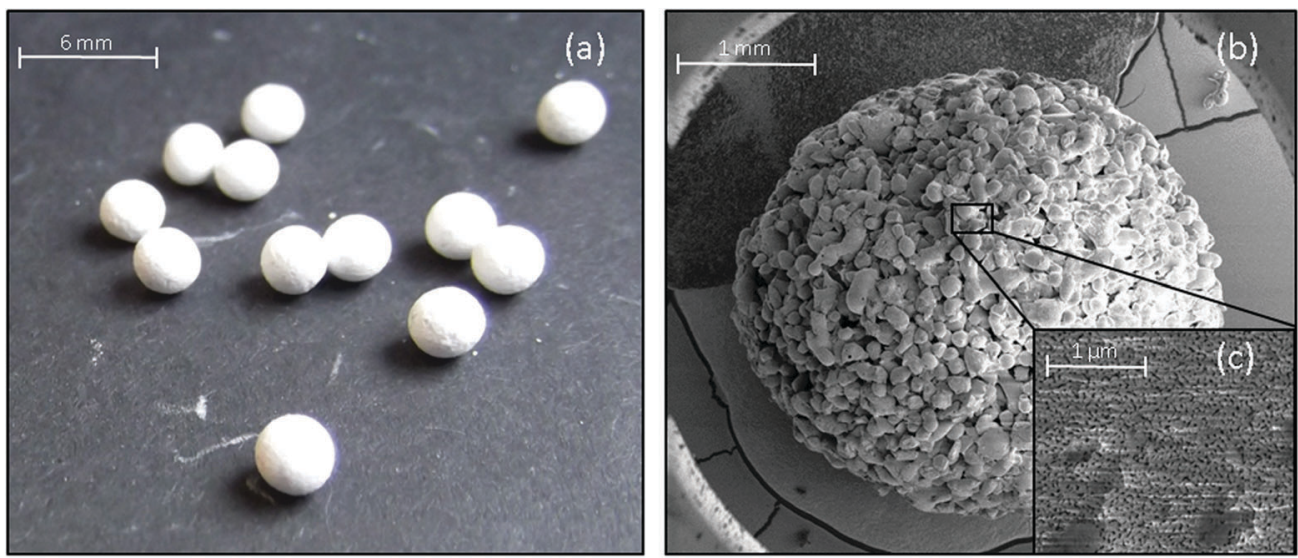

Fig. 21 Stable hierarchically structured silica beads composed of sintered glass particles of size fraction 80-100 $\mu \mathrm{m}$ : photograph (a) and SEM images indicating the additional (b) and the leaching-based (c) pore system. 


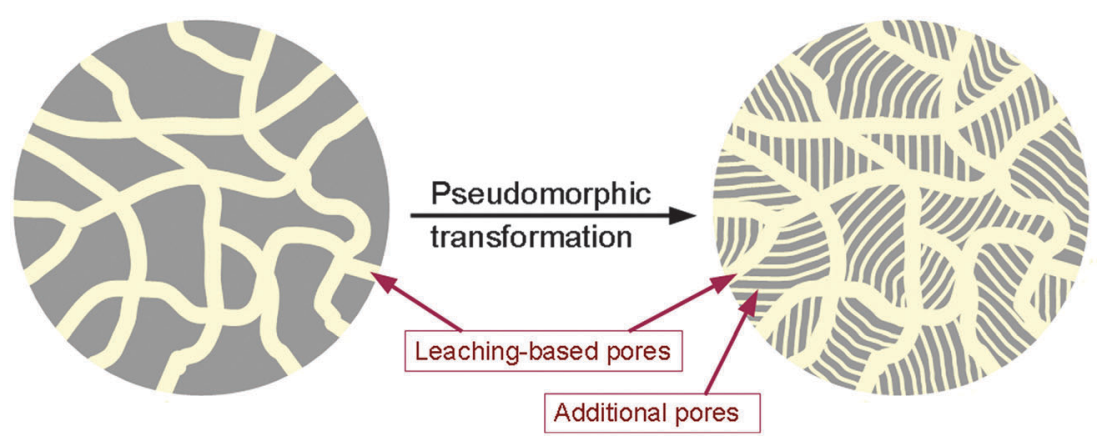

Fig. 22 Schematic illustration of the sponge-like pore system of a porous glass body (left) and the hierarchical pore system obtained via pseudomorphic transformation of the glass pore walls into the porous material (right).

achievable, then an alternative way is to transform the glass walls while the leaching-based pores are "protected" by a filler material (see Section 2.2.2).

2.2.1. Direct transformation. There are several studies on the direct transformation of porous glasses either into zeolitic or MTS monoliths, which we have already reviewed in $2013 .^{15}$

In the case of transformation into zeolites, the focus was usually on obtaining granules, beads or discs of MFI-type and BEA structure types and not on preserving the leaching-based pore system, though there was usually a random intraparticle porosity present, which was accessible from the outside (e.g. during mercury intrusion experiments) and thus formed together with the zeolitic micropores a hierarchical pore system within the obtained zeolitic shapes. ${ }^{33-35}$ However, there is at least one example where the transformation seems to be pseudomorphic in the exact sense as evidenced by SEM images (Fig. 23), which indicate the maintenance of the initial spongelike pore morphology. ${ }^{34}$ The formation of a hierarchical zeolitic material in the presence of monopropylamine as a template was further affirmed by a micropore volume increase from 0.007 to $0.110 \mathrm{~cm}^{3} \mathrm{~g}^{-1}$, while the macropore volume (leachingbased glass pores) was only slightly reduced from 1.27 down to $0.81 \mathrm{~cm}^{3} \mathrm{~g}^{-1}$. The presented studies showed that the type of micropore template in the reaction mixture and the initial pore diameter of the porous glass significantly influenced the path of crystallisation.
There are also reports on the (partial) transformation of porous glass discs into zeolite membranes. Dong et al. prepared such membranes via a gas-phase transformation in the presence of ethylenediamine and tri- $n$-propylamine as the templates. ${ }^{36}$ However, due to the targeted application of the membranes for the separation of small gas molecules, the aim of these studies was not to obtain hierarchical porosity within the membranes.

In general, almost no new work on the transformation of porous glasses into zeolites has been published during the past 10 years. To our knowledge, the only recent study is from 2012, which dealt with the shape-preserving transformation of porous glass discs into zeolitic membranes by treating the porous glass discs hydrothermally in the presence of triisopropyl ammonium templates and an additional silica source. ${ }^{37}$

While the transformation of porous glasses into zeolitic materials has already been examined in the 1990s by Schwieger et al. ${ }^{38}$ the pseudomorphic transformation of porous glasses into micellar templated silica (MTS) shapes has only recently been facilitated, ${ }^{16,39}$ although other amorphous silica materials like silica gels have already been transformed into MTS materials since the pioneering studies of Galarneau and Fajula in 2002. ${ }^{40-42}$ Such MTS particles were used as a column material for HPLC, for the entrapment of drugs or as catalyst supports. ${ }^{43}$ Further applications include enzyme binding and sensor technology.

There are two different approaches for the transformation of porous glasses. The first approach uses the surfactant CTAB
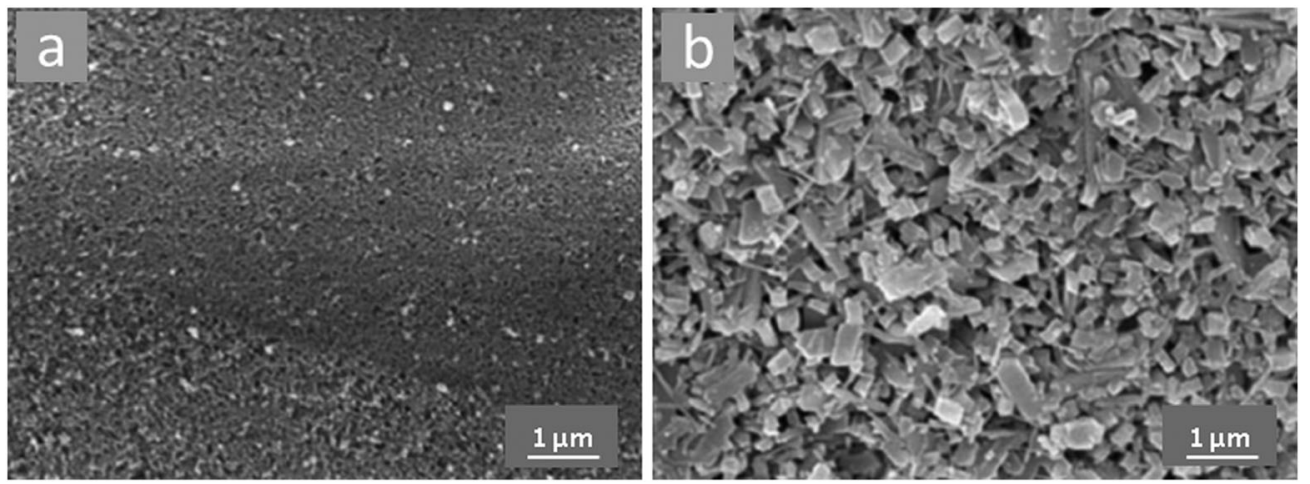

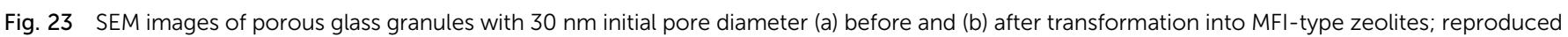
from ref. 34 with kind permission from Elsevier, Inc. 
(cetyltrimethylammonium bromide) combined with $\mathrm{NaOH},{ }^{16}$ which follows the procedure established by Galarneau et al. ${ }^{40}$ The second approach uses a solution of the surfactant CTAOH (cetyltrimethylammonium hydroxide), which is obtained via ion exchange of CTAB and which eliminates the need for $\mathrm{NaOH}$ during the transformation. ${ }^{39}$ For the transformation of porous glasses into MCM-41 the use of CTAOH has proven to be advantageous. This compound combines both functions that are necessary for the glass transformation, i.e. it acts as both a mesopore template and as an alkaline agent for silica dissolution. ${ }^{39}$ The high pore volumes and the steep increase of the nitrogen adsorption isotherm in the range of $0.3-0.4 p / p_{0}$ (sharp pore size distribution), which are typical for high-quality MCM-41, were only reached by using $\mathrm{CTAOH}$. In contrast, when $\mathrm{CTAB}$ and $\mathrm{NaOH}$ were applied for the glass transformation, reduced pore volumes after calcination above $500{ }^{\circ} \mathrm{C}$ were reported. ${ }^{16}$

How can such differences between the CTAOH approach and the $\mathrm{CTAB} / \mathrm{NaOH}$ approach be explained? We assume that in the $\mathrm{CTAB} / \mathrm{NaOH}$ approach the higher concentration of anions (bromide) and cations (sodium) hinders the interaction between the negatively charged silica species and the positively charged surfactant molecules, as schematically illustrated in Fig. 24. Accordingly, the $\mathrm{CTAOH}$ approach might enable a more effective attraction, which leads to a highly ordered MCM-41 material with pore volumes up to $1 \mathrm{~cm}^{3} \mathrm{~g}^{-1}$. The absence of sodium in the obtained MCM-41 material might also increase its hydrothermal and thermal stability. ${ }^{44}$

For the CTAOH approach the success and degree of the transformation of porous glasses into MCM-41 were dependent on the reaction time and temperature, the concentration of the surfactant $\left(\mathrm{CTA}^{+}\right)$, the alkalinity and on the characteristics of the starting porous glass (pore size and volume, wall thickness). ${ }^{39}$ The influence of the initial (leaching-based) pore size on the resulting pore morphology was illustrated on the basis of electron microscopic images, which are depicted in Fig. 25.

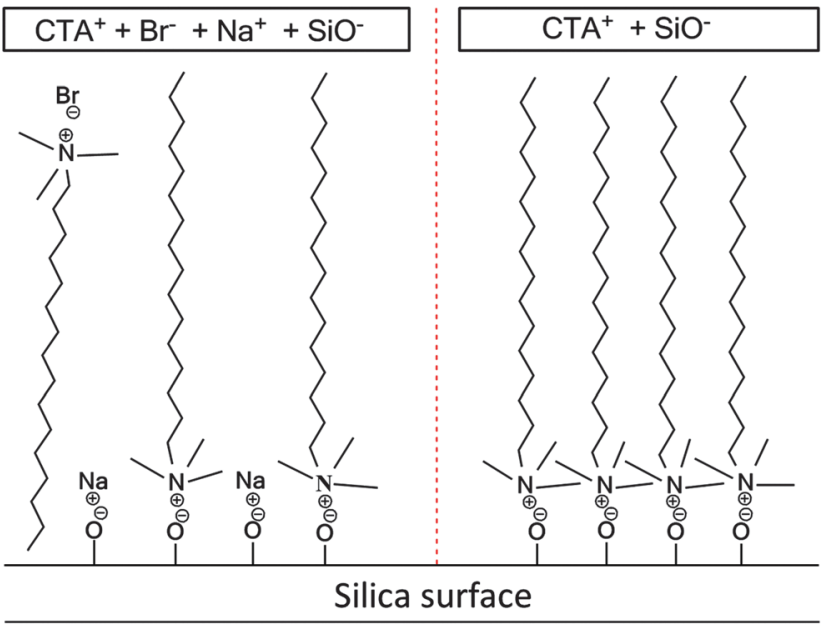

Fig. 24 Scheme of the suspected interactions between the glass (silica) surface and surfactant molecules $\left(\mathrm{CTA}^{+}\right)$in the transformation solution containing either $\mathrm{CTAB}$ and $\mathrm{NaOH}$ (left) or only $\mathrm{CTAOH}$ (right).
It turned out that the initial pore diameter of $150 \mathrm{~nm}$ enabled the best maintenance of the initial glass pore morphology during transformation in $1 \mathrm{M} \mathrm{CTAOH}$ solution, whereas larger pore diameters led to stronger tendencies towards glass pore dissolution, which hindered a pseudomorphic transformation.

The pseudomorphic transformation was optimised on the basis of the alkalinity by treating the porous glasses with mixed solutions of CTAOH and CTAB. ${ }^{39}$ The degree of transformation into MCM-41 correlated with the mesopore volume determined on the basis of $\mathrm{N}_{2}$ physisorption isotherms.

The SEM images in Fig. 26 showed that the initial glass (PGG-150, pore diameter of $150 \mathrm{~nm}$ ) as well as the resulting MCM-41 samples (PGG-150-0.xx) exhibit a sponge-like leachingbased pore morphology. Based on this high morphological similarity it could be concluded that the transformation was pseudomorphic in the exact meaning for all samples and led to a hierarchical pore system. However, broadening of the initial (leaching-based) pore size distribution in Fig. 26 (bottom right) indicates that complete transformation (PGG-150-1.00) led to a deformation of the leaching-based pore system.

Furthermore, it was observed from the SEM images in Fig. 26(top) as well as from the pore size distribution in Fig. 26(bottom right) that the leaching-based pore size in the transformation products is reduced compared to the initial glass. This effect can be explained by bulk density differences between the non-porous glass walls and the highly porous MCM41 structure. Accordingly, the glass pore wall swells into the free leaching-based pore volume during the transformation. If there is not enough space, the transformation will stop and a complete transformation cannot be reached. ${ }^{39}$ Based on the transformation experiments with porous glasses of different initial pore diameters and total pore volumes it was found that a minimum initial pore volume of about $1 \mathrm{~cm}^{3} \mathrm{~g}^{-1}$, pore diameters between ca. 60 and $300 \mathrm{~nm}$ and a well-adjusted CTAOH concentration are necessary to reach complete (pseudomorphic) transformation into hierarchical MCM-41 materials.

Very recently Guillot et al. ${ }^{16}$ synthesized a meso- and macroporous material via the transformation of a macroporous glass with a pore diameter of $100 \mathrm{~nm}$. The original macroscopic shape and the leaching-based pore structure of the starting glass could be retained. After functionalisation with aminopropyltriethoxy silane or mercaptopropyl silyl species in combination with hexacyanoferrate the composites were used as catalyst supports and in solid phase extraction processes.

2.2.2. "Pore-protected" pseudomorphic transformation. In addition to the previously described direct pseudomorphic transformation, hierarchically porous shapes can be synthesized using a method combining exotemplating ${ }^{45}$ and pseudomorphic transformation. In this way, the exotemplate protects the initial (leaching-based) pore system during the transformation step. Afterwards, the template has to be removed in order to release the leaching-based porosity of the transformed material. The feasibility of this procedure for the production of hierarchically porous MCM-41 beads from porous glass beads has recently been demonstrated. ${ }^{46}$ 


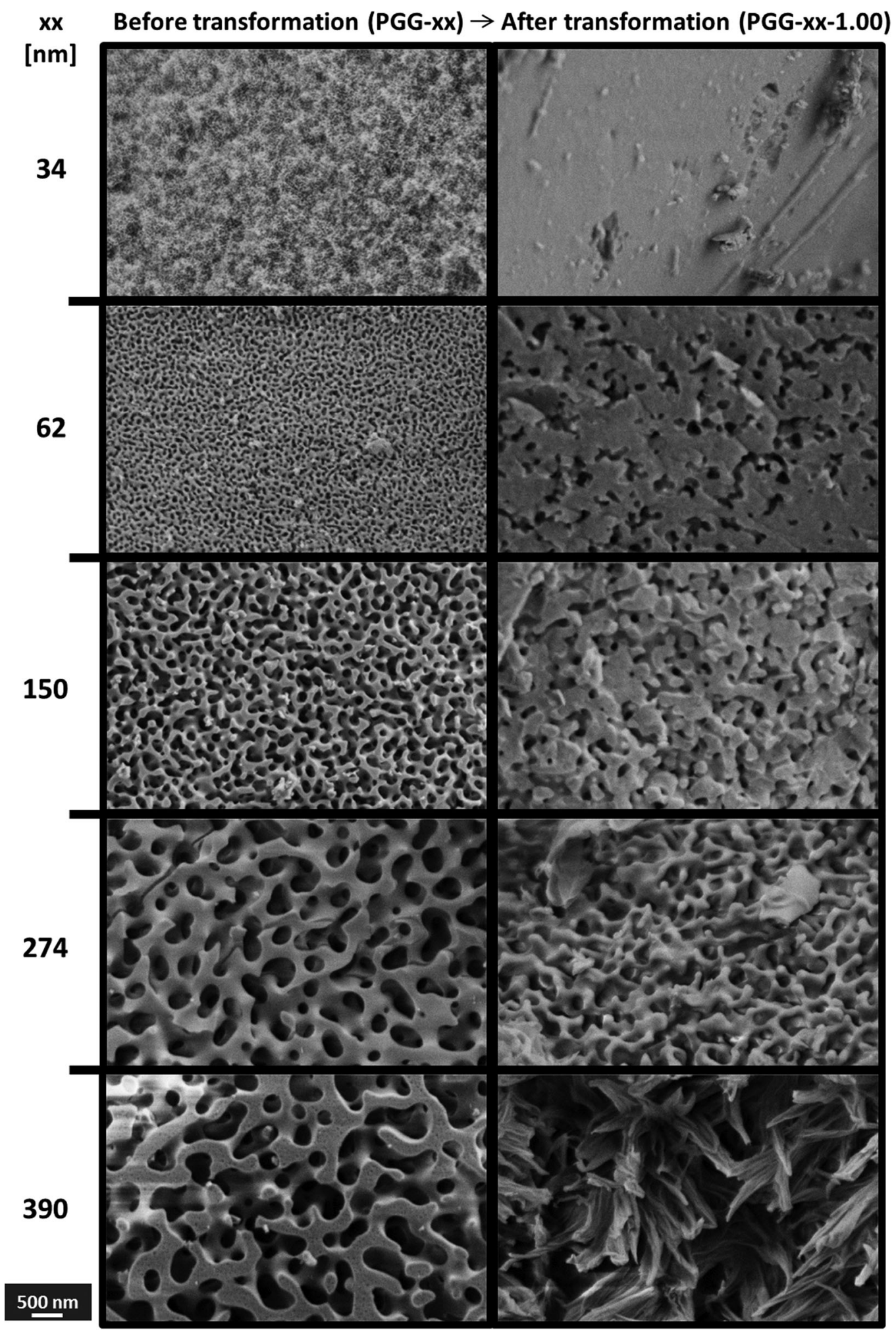

Fig. 25 SEM images of porous glass granules with different pore diameters before and after transformation into the MTS (MCM-41) material in the presence of $\mathrm{CTAOH}$; reproduced from ref. 39 with kind permission from Elsevier, Inc.

The first step of the pore-protected transformation is similar to the nanocasting procedure first introduced by Schüth ${ }^{47}$ and Lindén. ${ }^{48}$ The second step is then the pseudomorphic transformation. ${ }^{15,41,43}$ In a typical procedure, ${ }^{46}$ carbon negatives (precursor: mesophase pitch $^{49}$ ) of the initial porous glass beads are prepared and loaded with a silica gel by the classical sol-gel process. Prior to the carbon exotemplate removal, a pseudomorphic transformation of this pore-protected silica gel into 

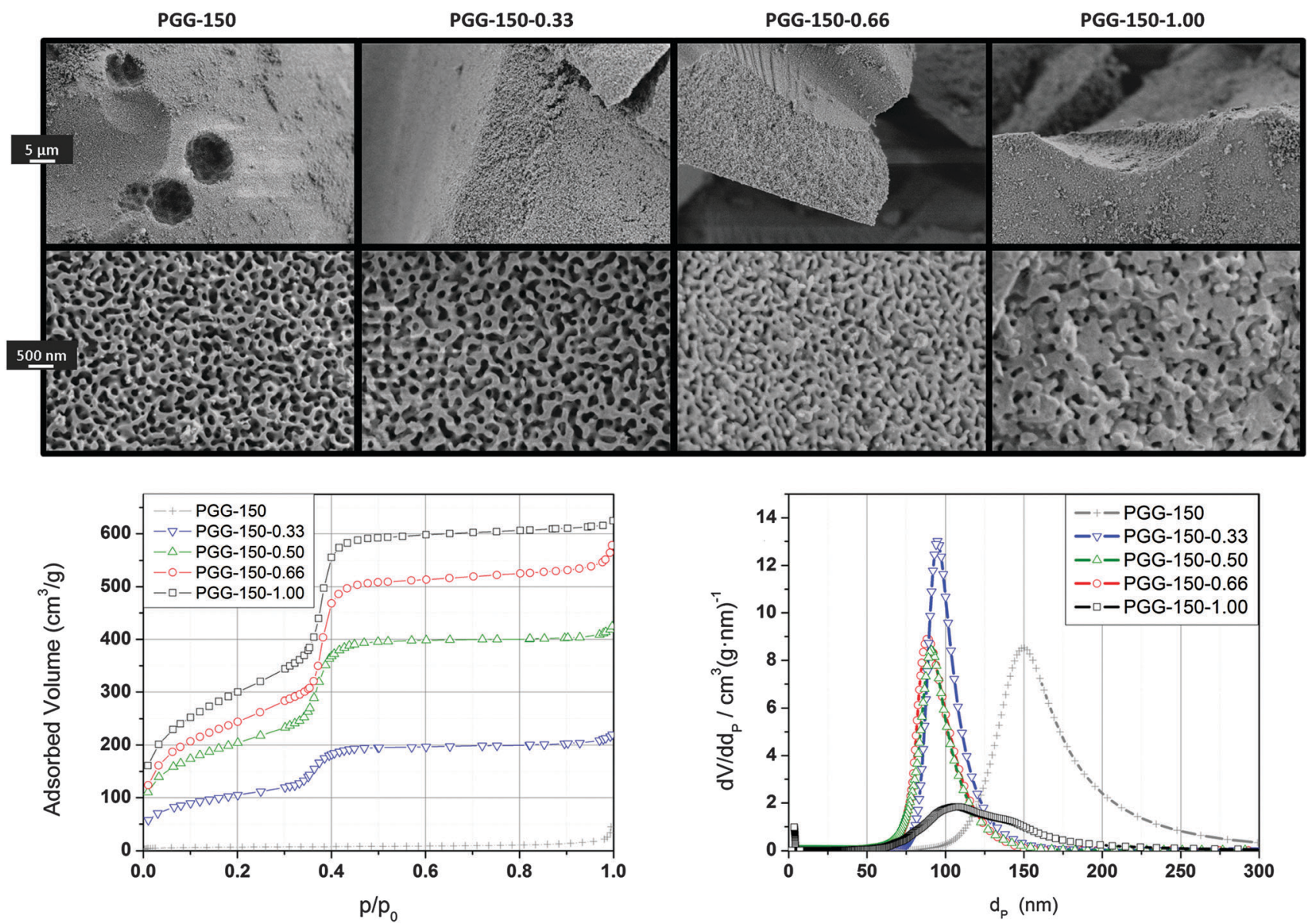

Fig. 26 SEM images (top), nitrogen physisorption isotherms (bottom left) and leaching-based pore size distributions from mercury intrusion (bottom right) of porous glass granules with an initial pore diameter of $150 \mathrm{~nm}$ before (PGG-150) and after different degrees of transformation into MCM-41; the conversion was adjusted on the basis of the $\mathrm{CTAOH} / \mathrm{CTA}^{+}$molar ratio $(0.33-1.00)$ by mixing $\mathrm{CTAOH}$ with $\mathrm{CTAB}$ in the reaction mixture. Adopted from ref. 39 with kind permission from Elsevier, Inc.

MCM-41 materials is carried out. Using porous glass as a template for the carbon replica enables us to reach previously not accessible pore size ranges and tortuosities in the finally resulting hierarchical MCM-41 beads. The substitution of the porous glass matrix (which exhibits non-porous walls) by the porous (loosely packed) silica gel prior to the pseudomorphic transformation is necessary to enable sufficient interaction between the transformation solution and the silica matrix since the leaching-based porosity is already blocked by the poreprotecting material.

SEM images of a porous glass bead with an initial pore diameter of $104 \mathrm{~nm}$ in different stages of the pore-protected transformation process are depicted in Fig. 27. These images indicate that not only the macroscopic shape of the original glass bead but also its spongy microstructure could be transferred into the carbon replica and finally into the MTS material. In contrast to the direct transformation of these glass beads, which resulted in hierarchical but partially collapsed MTS beads, the pore-protected transformation preserved the initial glass bead morphology completely.

Comparison of the textural data in Table 1 shows that the low specific surface area $\left(A_{\mathrm{BET}}\right)$ of $19 \mathrm{~m}^{2} \mathrm{~g}^{-1}$ of the macroporous glass could be transferred to the carbon negative with $25 \mathrm{~m}^{2} \mathrm{~g}^{-1}$, which indicates an almost nonporous material. In contrast, the final MTS material exhibits a high specific surface area due to the ordered mesoporous structure inside the leaching-based (macro)pore walls. Similar tendencies can be observed for the total pore volume $\left(V_{\text {tot }}\right)$ measured by nitrogen physisorption as well as mercury intrusion.

Comparison of the pore size distribution curves of the initial porous glass and the resulting carbon negative (Fig. 28(left)) shows a slight broadening for the leaching-based pore size distribution and shift towards larger diameters. Fragments caused by incomplete replication are indicated by a very small portion of larger pores. After the final transformation into the MTS material and calcination, the leaching-based pore size distribution is slightly broadened, which can be attributed to the partial collapse of the fragile scaffold during the highpressure mercury intrusion measurement. ${ }^{50}$

The nitrogen physisorption isotherms in Fig. 28(right) prove the absence of intrinsic micro/mesoporosity in the carbon replica. This observation emphasizes the advantage of applying a precursor with a very low amount of heteroatoms found in the mesophase pitch. ${ }^{49,51}$ Furthermore, after the transformation of 

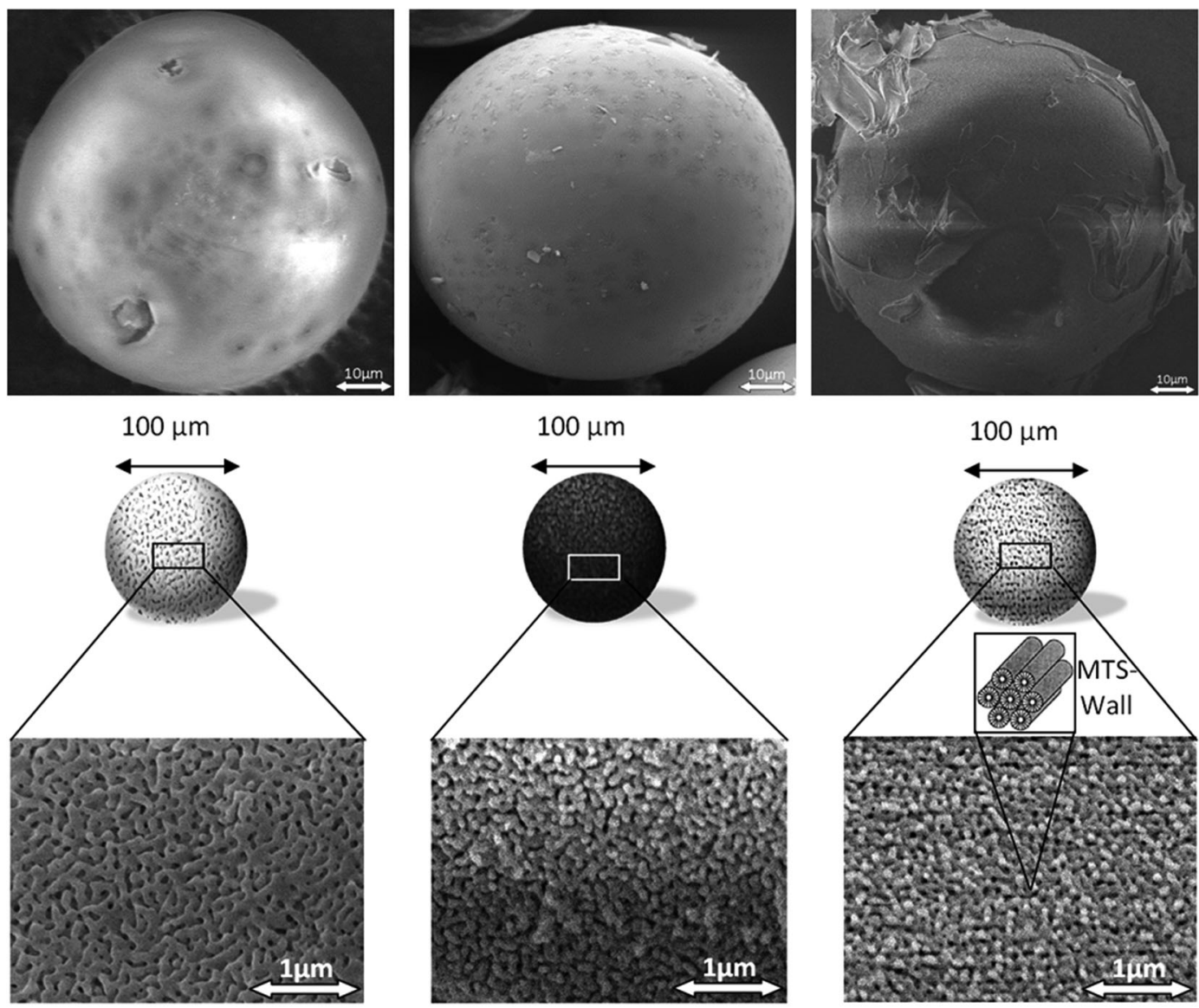

Fig. 27 SEM images of the macroscopic shape (upper row) and of the microstructure (below) of a porous glass bead with $104 \mathrm{~nm}$ pore diameter (left), the porous carbon replica (middle) and the hierarchical (meso-macroporous) silica bead after the second replication step (right); reproduced from ref. 46 with kind permission from John Wiley and Sons, Inc.

Table 1 Textural properties of central species formed during the pore-protected transformation of porous glass beads into hierarchical MTS beads; reproduced from ref. 46 with kind permission from John Wiley and Sons, Inc

\begin{tabular}{lllllll}
\hline Sample & $A_{\mathrm{BET}}\left(\mathrm{m}^{2} \mathrm{~g}^{-1}\right)$ & $d_{\mathrm{P}, \text { meso }}(\mathrm{nm})$ & $V_{\text {tot,N2 }}\left(\mathrm{cm}^{3} \mathrm{~g}^{-1}\right)$ & $d_{\mathrm{P}, \text { macro }}(\mathrm{nm})$ & $V_{\text {tot,Hg }}\left(\mathrm{cm}^{3} \mathrm{~g}^{-1}\right)$ & $d_{\text {Particle,mean }}(\mu \mathrm{m})$ \\
\hline Porous glass & 19 & - & 0.03 & 104 & 0.46 & 96 \\
Carbon negative & 25 & - & 0.03 & 152 & 0.44 & 80 \\
MTS & 658 & 4.1 & 0.81 & 114 & 0.88 & 74
\end{tabular}

the silica phase inside the carbon macropores to MTS, the material exhibits uniform mesopores (additional pores) - represented by a steep rise of the adsorption isotherm between 0.3 and $0.4 p / p_{0}$.

Additionally, XRD measurements were carried out to analyze the arrangement of the mesopores in the walls between the leaching-based macropores. The corresponding XRD pattern is embedded in Fig. 28(bottom right). The (100) reflection at about $2^{\circ} 2$ theta as well as the weak (110) and (200) reflexes at around $4^{\circ} 2$ theta are typical for hexagonally arranged mesopores in a MCM-41 type material. ${ }^{52}$

The above results indicate that the "pore-protected" transformation is an option to convert porous materials with sensitive textural properties in a pseudomorphic manner. During the transformation into the MTS material, the macroscopic geometry, the morphology and the textural properties of the leaching-based macropore system can be preserved to a large extent, resulting in hierarchical MTS shaped bodies.

However, the application of this procedure is limited by the potential incompatibility between the viscosity and molecular dimensions of the exotemplate (=pore-protecting agent) and the tortuosity and pore size of the host material. For this reason, the pore-protected transformation is mainly applicable for macroporous starting materials.

\section{Perspectives}

Porous glass monoliths with a hierarchical micro/macro- to macro/macro pore system are now available. The new materials can be prepared using various approaches such as 

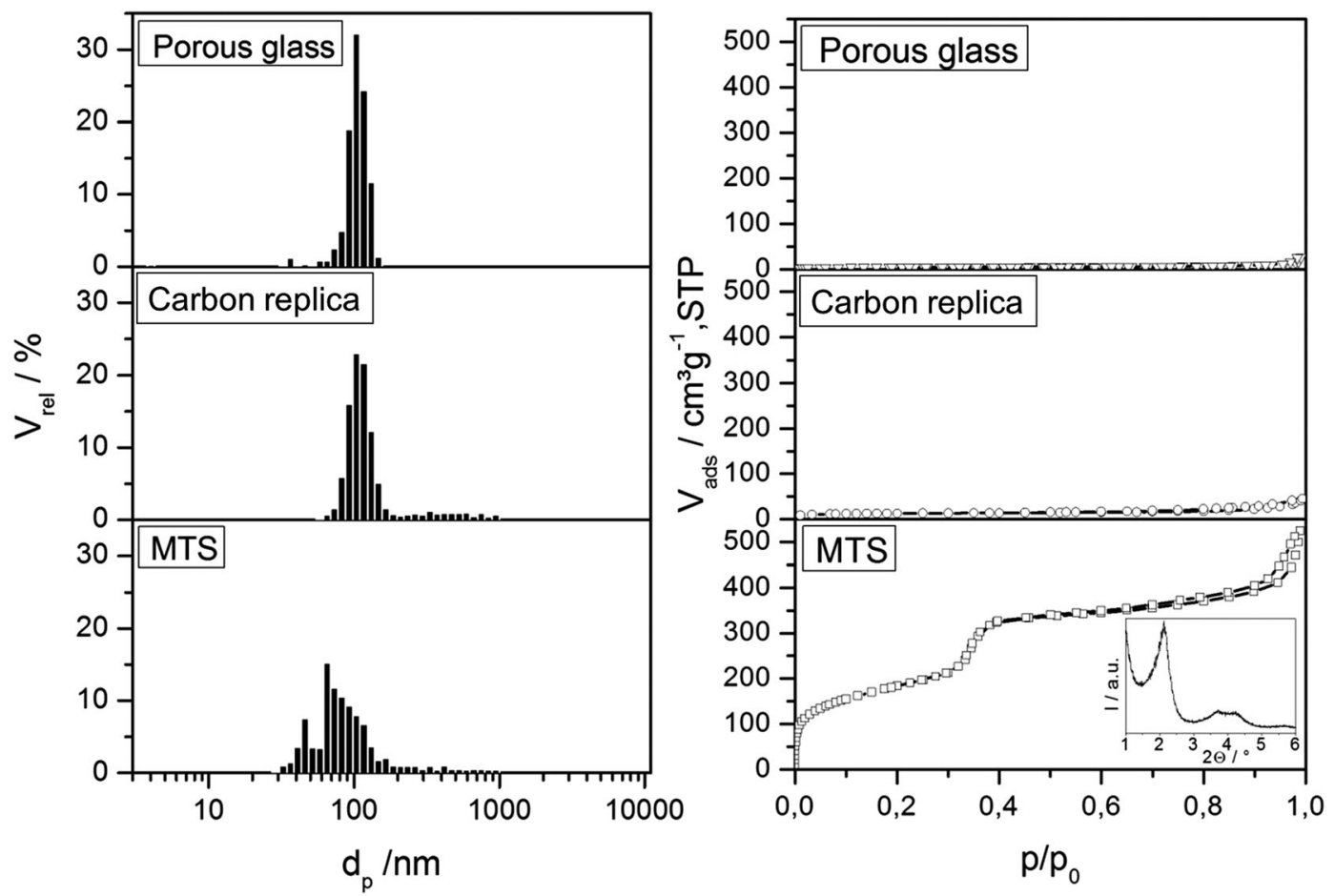

Fig. 28 Pore size distributions from mercury intrusion (left) and nitrogen physisorption isotherms (right) of the starting porous glass (top), the inverse carbon replica (middle) and of the transformation product (bottom); inset: XRD pattern of the transformation product (MTS); reproduced from ref. 46 with kind permission from John Wiley and Sons, Inc.

(I) sintering processes yielding macroscopic porous monoliths, followed by the introduction of the leaching-based glass pore system within the walls of the pore system of the monolithic preform,

(II) (pseudomorphic) glass transformation yielding hierarchical shapes with an additional micro- or mesopore system inside the leaching-based glass pore walls.

In the first case, different forming techniques can be applied to generate the sodium borosilicate glass-based preforms: (i) pressing of glass beads in the presence of inorganic salt, polymer and water, (ii) impregnation of open cell polymeric foams with a glass slurry of defined viscosity, (iii) freeze-casting of a mixture of glass powder, camphene and a binder, (iv) bundling of glass tubes using the drawdown technique or (v) ionotropic gelation. These process steps are followed by a sintering step under defined conditions resulting in mechanically stable macroporous sodium borosilicate monoliths. Finally, a thermally induced phase separation in combination with selective leaching generates an additional (leaching-based) porosity inside the walls of the monolithic preform, by which the hierarchical pore system is obtained.

In the second case, hierarchically porous zeolitic or ordered mesoporous silica shapes are obtained by (pseudomorphic) transformation of preformed porous glass shapes. Here, the hierarchy is generated via the partial or complete transformation of the glass walls through locally restricted dissolution and precipitation processes. In addition, it was shown that the application of the carbon replica technique enables a "pore-protected" transformation of meso- or macroporous glass beads, using a silica gel intermediate as the starting material for the pseudomorphic transformation. This technique facilitates a better preservation of the leaching-based meso- or macropore size and of the wall thickness in the resulting hierarchical MCM- 41 beads on the basis of porous glasses.

The new hierarchically porous glass monoliths extend the available macropore size range of conventional silica monoliths, which are prepared via polymer-induced phase separation in a sol-gel process in both directions. While for sol-gel materials the macropore size (and the associated thickness of the silica skeleton) can be adjusted in the range between 1 and $30 \mu \mathrm{m}$, glass monoliths prepared via sintering processes allow a variation in the macropore size (additional pore system) from $10 \mu \mathrm{m}$ up to several millimeters. By applying bundled glass tubes even monoliths with unidirectionally oriented macropores can be generated.

While in the case of sol-gel monoliths reproducible macropores with diameters below $1 \mu \mathrm{m}$ are only difficult to be achieved, and glass monoliths allow a leaching-based pore size in the range between $50 \mathrm{~nm}$ and $10 \mu \mathrm{m}$ and are thus interesting starting materials. A partial or complete pseudomorphic transformation of the non-porous silica skeleton integrates an ordered mesoporosity (additional pores) in the material. Only partial transformation of the glass walls into a MCM-41/48 like phase results in monoliths with very high mechanical stability and a large specific surface area, which can be dried very fast and crack free under ambient conditions.

The new hierarchically porous silica materials on the basis of porous glasses possess potential for applications as microreactors 
for catalytic processes in continuous flow mode. The different synthesis routes enable the control of various applicationoriented parameters like size, volume and tortuosity of the flow-through macropores, skeleton thickness, size and ordering of the leaching-based intra-skeleton mesopores with yet unknown flexibility of the textural properties. Another drawback of sol-gel monoliths is the fact that mostly special polymers (polytetrafluoroethylene) have to be used for their cladding. This leads to problems for applications under high pressure or temperature. In the case of the hierarchically porous glass monoliths an alternative route is evolving: the monoliths can be cladded with a thick engirding glass tube through combined fusion and evacuation. As a result of the low softening point of the glass tube the pore structure of the glass monoliths will remain unchanged during the cladding process. The resulting reactors are stable at high temperatures (up to $600{ }^{\circ} \mathrm{C}$ ) and pressures.

The application of the starting glasses in the form of powder or as small beads opens the route for the generation of hierarchically structured silica monoliths via 3D laser sintering in combination with selective leaching and pseudormorphic transformation. Monolithic materials with virtually any adjustable morphology of flow-through macropores (additional pores) and silica skeleton can be generated using this innovative approach. The mechanical stability of the monoliths can be controlled via the degree of porosity (leaching-based pores) in the silica skeleton, i.e. if only a porous layer is present at the macropore surface then the mechanical stability will remain higher compared to the condition when the monolithic walls are completely transformed into porous silica.

Finally, meso- or macroporous glass membranes can be used as components for optical chemosensors. ${ }^{53}$ The integration of a hierarchical porosity can improve the mass transfer in the membrane component. This is reflected by a reduced response time of the whole sensor.

Studies on all three applications (microreactors, 3D laser sintering and membranes for sensor applications) are currently carried out.

\section{Acknowledgements}

D. E. and C. K. gratefully acknowledge the financial support from the German Research Foundation (DFG) within the priority programme (SPP 1570) "Porous media with defined pore structure: synthesis, modelling, and application" (EN 942/2-1 and EN 942/5-2). S. K. expresses her gratitude to Kerstin Pfeifer and Daniel Possner for their contributions to the production of glass bundles using the drawdown technology. A. I. would like to thank the DFG for funding through the Cluster of Excellence 'Engineering of Advanced Materials' (EAM).

\section{References}

1 D. Enke, F. Janowski and W. Schwieger, Porous glasses in the 21st century-a short review, Microporous Mesoporous Mater., 2003, 60, 19-30.
2 F. Janowski and D. Enke, in Handbook of Porous Solids, ed. F. Schüth, K. S. W. Sing and J. Weitkamp, Wiley-VCH, Weinheim, 2002, vol. 3, pp. 1432-1542.

3 F. Janowski, G. Fischer, W. Urbaniak, Z. Foltynowicz and B. Marciniec, J. Chem. Technol. Biotechnol., 1991, 51, 263-272.

4 K. Engelmark Cassimjee, M. Kadow, Y. Wikmark, M. Svedendahl Humble, M. L. Rothstein, D. M. Rothstein and J.-E. Backvall, Chem. Commun., 2014, 50, 9134-9137.

5 T. Yazawa, F. Machida, N. Kubo and T. Jin, Ceram. Int., 2009, 35, 3321-3325.

6 M. Anpo, N. Aikawa, Y. Kubokawa, M. Che, C. Louis and E. Giamello, J. Phys. Chem., 1985, 89, 5017-5021.

7 J. Kullmann, D. Enke, S. Thränert, R. Krause-Rehberg and A. Inayat, Colloids Surf., A, 2010, 357, 17-20.

8 T. Titze, C. Chmelik, J. Kullmann, L. Prager, E. Miersemann, R. Gläser, D. Enke, J. Weitkamp and J. Kärger, Angew. Chem., Int. Ed., 2015, 54, 5060-5064.

9 A. Cizman, W. Bednarski, T. V. Antropova, O. Pshenko, E. Rysiakiewicz-Pasek, S. Waplak and R. Poprawski, Composites, Part B, 2014, 64, 16-23.

10 O. A. Pshenko, I. A. Drozdova, I. G. Polyakova, K. Rogacki, A. Cizman, R. Poprawski, E. Rysiakiewicz-Pasek and T. V. Antropova, Glass Phys. Chem., 2014, 40, 167-172.

11 T. V. Antropova, I. N. Anfimova, I. V. Golosovsky, Yu. A. Kibalin, A. A. Naberezhnov, N. I. Porechnaya, O. A. Pshenko and A. V. Filimonov, Phys. Solid State, 2012, 54, 2106-2111.

12 M. Hasanuzzaman, M. Sajjia, A. Raffwerty and A.G. Olabi, Thermal behavior of zircon/zirconia-added chemically durable borosilicate porous glass, http://www.thehealthwell.info/node/ 667275, accessed August 2014.

13 A. Barascu, J. Kullmann, B. Reinhardt, T. Rainer, H. Roggendorf, M. Dubiel and D. Enke, J. Am. Ceram. Soc., 2012, 95, 3013-3015.

14 W. Schwieger, A. G. Machoke, T. Weissenberger, A. Inayat, T. Selvam, M. Klumpp and A. Inayat, Chem. Soc. Rev., 2015, DOI: $10.1039 / \mathrm{c} 5 \mathrm{cs} 00599 \mathrm{j}$.

15 A. Inayat, B. Reinhardt, H. Uhlig, W.-D. Einicke and D. Enke, Chem. Soc. Rev., 2013, 42, 3753-3764.

16 M. Guillot, S. E. Mourabit, J. Ravaux, A. Tokarev, F. Goettmann and A. Grandjean, Microporous Mesoporous Mater., 2014, 197, 83-91.

17 A. Galarneau, A. Sachse, B. Said, C.-H. Pelisson, P. Boscaro, N. Brun, L. Courtheoux, N. Olivi-Tran, B. Coasne and F. Fajula, C. R. Chim., 2016, 19, 231-247.

18 M. E. Nordberg, J. Am. Ceram. Soc., 1944, 27, 299-305.

19 B. Reinhardt, D. Enke and F. Syrowatka, J. Am. Ceram. Soc., 2012, 95, 461-465.

20 E. M. Rabinovich, J. Mater. Sci., 1985, 20, 4259-4297.

21 F. B. Siebers, N. Greulich and W. Kiefer, Glastech. Ber., 1989, 62, 63-73.

22 M. Scheffler, P. Colombo and J. Binner, Cellular Ceramics Structure, Manufacturing, Properties and Applications, WILEY-VCH Verlag GmbH \& Co. KGaA, Weinheim, 2005.

23 K. Schwartzwalder and A. V. Somers, US Pat., $3090094,1963$.

24 A. Jacobi, Transparent sponges as built-in component in photo-bio-reactors (II): Concepts and applications, Scientific 
Colloquium: Sponge Packings in Process Engineering - Basics and Applications, Karlsruhe, 2012.

25 B. Reinhardt, J. Herwig, S. Rannabauer, M. Scheffler and D. Enke, J. Eur. Ceram. Soc., 2014, 34, 1465-1470.

26 A. Hesse, S. Mrotzek, D. Hülsenberg and E. Rädlein, Microsyst. Technol., 2008, 14, 1541-1544.

27 S. Krenkel, H. Uhlig, D. Enke and E. Rädlein, Phys. Chem. Glasses: Eur. J. Glass Sci. Technol., Part B, 2015, 56, 149-158.

28 S. Deville, Adv. Eng. Mater., 2008, 10, 155-169.

29 B. Reinhardt, Poröse Gläser - Konzepte zur Generierung hierarchischer Porenstrukturen, PhD thesis, University of Leipzig, in German, 2014.

30 D. A. Porter and K. E. Easterling, Phase transformations in metals and alloys, Chapman \& Hall, London, 2nd edn, 1992.

31 T. Y. Klein, L. Treccani and K. Rezwan, J. Am. Ceram. Soc., 2012, 95, 907-914.

32 C. Küster, M. Münzner, B. Reinhardt and D. Enke, Preparation of porous, hierarchically organized silica beads via combination of ionotropic gelation, sintering and phase separation, 2016, submitted.

33 T. Selvam, G. T. P. Mabande, M. Köstner, F. Scheffler and W. Schwieger, Stud. Surf. Sci. Catal., 2004, 154A, 598-605.

34 M. Rauscher, T. Selvam, W. Schwieger and D. Freude, Microporous Mesoporous Mater., 2004, 75, 195-202.

35 F. Scheffler, W. Schwieger, D. Freude, H. Liu, W. Heyer and F. Janowski, Microporous Mesoporous Mater., 2002, 55, 181-191.

36 W.-Y. Dong and Y.-C. Long, Microporous Mesoporous Mater., 2004, 76, 9-15.

37 T. Peppel, B. Paul, R. Krähnert, D. Enke, B. Lücke and S. Wohlrab, Microporous Mesoporous Mater., 2012, 158, 180-186.

38 W. Schwieger, M. Rauscher, F. Scheffler, D. Freude, U. Pingel and F. Janowski, Proceedings of the 12th
International Zeolite Conference, Baltimore, USA, July, 1998, pp. 1849-1856.

39 H. Uhlig, M.-L. Gimpel, A. Inayat, R. Gläser, W. Schwieger, W.-D. Einicke and D. Enke, Microporous Mesoporous Mater., 2013, 182, 136-146.

40 T. Martin, A. Galarneau, F. Di Renzo, F. Fajula and D. Plee, Angew. Chem., Int. Ed., 2002, 41, 2590-2592.

41 A. Galarneau, J. Iapichella, K. Bonhomme, F. Di Renzo, P. Kooyman, O. Terasaki and F. Fajula, Adv. Funct. Mater., 2006, 16, 1657-1667.

42 J. Babin, J. Iapichella, B. Lefevre, C. Biolley, J.-P. Bellat, F. Fajula and A. Galarneau, New J. Chem., 2007, 31, 1907-1917.

43 S. Bhattacharyya, G. Lelong and M.-L. Saboungi, J. Exp. Nanosci., 2006, 1, 375-395.

44 T. R. Pauly, V. Petkov, Y. Liu, S. J. L. Billinge and T. J. Pinnavaia, J. Am. Chem. Soc., 2002, 124, 97-103.

45 A. Stein, Microporous Mesoporous Mater., 2001, 44, 227-239. 46 C. Küster, B. Reinhardt, M. Fröba and D. Enke, Z. Anorg. Allg. Chem., 2014, 640, 565-569.

47 A. H. Lu, W. Schmidt, A. Taguchi, B. Spliethoff, B. Tesche and F. Schüth, Angew. Chem., Int. Ed., 2002, 41, 3489-3492.

48 J.-H. Smått, C. Weidenthaler, J. B. Rosenholm and M. Lindén, Chem. Mater., 2006, 18, 1443-1450.

49 K. Jian, T. C. Truong, W. P. Hoffman and R. H. Hurt, Microporous Mesoporous Mater., 2008, 108, 143-151.

50 R. Pirard and J.-P. Pirard, Stud. Surf. Sci. Catal., 2000, 128, 603-611.

51 J. Parmentier, S. Saadhallah, M. Reda, P. Gibot, M. Roux, L. Vidal, C. Vix-Guterl and J. Patarin, J. Phys. Chem. Solids, 2004, 65, 139-146.

52 M. Kruk, M. Jaroniec, J. M. Kim and R. Ryoo, Langmuir, 1999, 15, 5279-5284.

53 R. Mueller, N. Anders, J. Titus and D. Enke, Talanta, 2013, 107, 255-262. 